\title{
SLC9/NHE gene family, a plasma membrane and organellar family of $\mathrm{Na}^{+} / \mathrm{H}^{+}$exchangers *
}

\author{
Mark Donowitz ${ }^{\mathrm{a},}$, C. Ming Tse ${ }^{\mathrm{a}}$, and Daniel Fuster ${ }^{\mathrm{b}}$ \\ aDepartments of Medicine and Physiology, Johns Hopkins University School of Medicine, \\ Baltimore, MD, United States ${ }^{b}$ Department of Nephrology and Hypertension, GNI Institute of \\ Biochemistry and Molecular Medicine, University Hospital of Bern, Switerland
}

\begin{abstract}
This brief review of the human $\mathrm{Na} / \mathrm{H}$ exchanger gene family introduces a new classification with three subgroups to the SLC9 gene family. Progress in the structure and function of this gene family is reviewed with structure based on homology to the bacterial $\mathrm{Na} / \mathrm{H}$ exchanger NhaA. Human diseases which result from genetic abnormalities of the SLC9 family are discussed although the exact role of these transporters in causing any disease is not established, other than poorly functioning NHE3 in congenital Na diarrhea
\end{abstract}

\section{Keywords}

SLC9; Na/H exchanger gene family; Antiporter; 1:1 stoichiometry; Na absorption; Intracellular $\mathrm{pH}$

\section{Introduction}

This gene family is involved in $\mathrm{pH}$ homeostasis of the cytosol and intracellular organelles, is the major way $\mathrm{Na}^{+}$is absorbed in the kidney and GI tract and includes isoforms that cycle between the plasma membrane and intracellular organelles as well as those that are static in the plasma membrane and perhaps in intracellular organelles. In addition, it is beginning to be apparent that the members of this gene family contribute to the pathophysiology of multiple human diseases. This brief review is an attempt to summarize current progress in all these areas for this diverse gene family.

The human $\mathrm{Na}^{+} / \mathrm{H}^{+}$exchangers (Table 1) are encoded by the SLC9 gene family of the Solute Carrier classification of transporters (SLC, HUGO nomenclature, http:// www.genenames.org) and are a subgroup of the eukaryotic and prokaryotic monovalent cation proton antiporter (CPA) superfamily (Transport Protein database http://tcdb.ucsd.edu/ $\mathrm{tcdb} /$ ) (Brett et al., 2005b; Orlowski and Grinstein, 2004). SLC9 has three subfamilies (Fig. 1): SLC9A: $\mathrm{Na}^{+} / \mathrm{H}^{+}$antiporters (nine family member paralogs in the human genome, SLC9A1-9, encoding NHE1-9 with one established (NHE6) and one possible (NHE1) splice variant and five pseudogenes). SLC9B: $S L C 9 B 1$ and $S L C 9 B 2$ encoding NHA1 and NHA2 respectively, with NHA1 having a splice variant. SLC9C: $S L C 9 C 1$ encodings perm

\footnotetext{
* Publication in part sponsored by the Swiss National Science Foundation through the National Center of Competence in Research (NCCR) TransCure, University of Bern, Switzerland; Director Matthias A. Hediger; Web: http://www.transcure.ch.

(c) 2012 Elsevier Ltd. All rights reserved.

*Corresponding author. mdonowit@jhmi.edu (M. Donowitz).
} 
NHE, and $S L C 9 C 2$. Subfamily A is part of CPA1 (transporter classification database $=\mathrm{TC}$ 2A 36. 1-9), B is part of CPA2, and C is part of NaT-DC (Na-transporting carboxylic acid decarboxylase) with the SLC9C members of Nat-DC being questionable members since they do not cluster with other mammalian NHEs and only weakly associate with other members of the NaT-DC gene family (Brett et al., 2005b). The evolution of this gene family has been described in detail (Brett et al., 2005b; Orlowski and Grinstein, 2004).

\section{SLC9 structure (Fig. 2)}

The structure has not been solved for any member of the SLC9 family. However, a great deal of structural information is known. All NHEs are organized in a similar fashion with an $\sim 450$ aa $\mathrm{N}$-terminus being made up of 11 or 12 membrane spanning domains and carrying out the $\mathrm{Na}^{+}$and $\mathrm{H}^{+}$exchange and the varying length intracellular C-terminal domain ( 125440 amino acids, based on the isoform) being involved in regulation of the exchange activity (Table 1; Donowitz et al., 2009). There is evidence that the C-terminus associates with both intracellular aspects of the $\mathrm{N}$-terminus and also with the inner leaflet of the plasma membrane via interactions with negatively charged phospholipids (PS, PIP2, PIP3) (Ikeda et al., 1997; Alexander et al., 2011). In spite of the SLC9 structures not having been directly solved, based on homology modeling using the solved structure of the E. coli $\mathrm{Na}^{+} / \mathrm{H}^{+}$ antiporter NhaA (Hunte et al., 2005; Padan et al., 2009), the general view is that the basic structure of the SLC9 transport domain is known. Specifically bioinformatic analyses with use of fold alignment algorithms supplemented with some mutagenesis studies of NHE1 and NHA2 have been performed in spite of the amino acid alignment of NhaA and the SLC9 members being 10\% (Landau et al., 2007; Schushan et al., 2010). In addition, structural information has been gained via study of NHE1 using cysteine scanning mutagenesis formed on cysteine-less mutants (Wakabayashi et al., 2000). These two approaches have not led to identical models and we describe our interpretations of an ongoing area of research. The transport of $\mathrm{Na}^{+}$and $\mathrm{H}^{+}$in the NHEs occurs in the center of the $\mathrm{N}$-terminus via a two inverted funnel area that is made up of two transmembrane helices which in some cases cross each other and contain charged residues forming dipoles that are modified by surrounding oppositely charged residues. This area undergoes conformational changes in the transport cycles and carries out the $\mathrm{Na}^{+}$and $\mathrm{H}^{+}$exchange. This funnel organization for the transport function is now known to be used by at least 12 gene families (sodium-dependent bile acid cotransporter encoded by SLC1OA2 and, SGLT1 encoded by SLC5A1, among others) and may be the generally used organization of the transport domain of cotransporters and antiporters (Nien-Jen et al., 2011). The structure in addition contains a pH sensor which is involved in the role of regulation of the exchange function by intracellular $\mathrm{H}^{+}$in addition to the transport of protons, which is structurally separate from the transport funnel and a dimerization domain (Padan et al., 2009). All SLC9 members appear to exist as dimers and while transport function occurs as a monomer, the dimerization is believed to provide stability of the molecule. The major difference in interpretation of the SLC9 structure from the two approaches relates to the N-terminal membrane spanning domains. What is considered membrane spanning domains 1 and 2 by the cysteine scanning mutagenesis approach is felt by homology to NhaA not to be membrane spanning domains at all. This domain does not appear to be important for any NHE function and has been suggested as being cleaved off, including via the presence of putative signal sequences for some NHEs.

\section{SLC9A/NHE family}

\subsection{SIc9a1 - NHE1}

The human NHE1 protein, encoded by SLC9A1, is 815 amino acids long and contains a hydrophobic N-terminal membrane domain of 500 amino acids responsible for NHE 
transport and a hydrophilic, intracellular 315 amino acid long C-terminus that is necessary for NHE1 regulation. Plasmalemmal NHE1 is both $N$ - and $O$-glycosylated, but glycosylation is not required for transport function. NHE1 is highly sensitive to amiloride and is also sensitive to lipophilic amiloride derivatives including ethylisopropylamiloride (EIPA) and the benzoylguanidines HOE694 and cariporide.

NHE1 is present in most mammalian cells. Exceptions lacking NHE1 are macula densa and $a$ - and $\beta$-intercalated cells of the kidney. NHE1 resides almost exclusively on the surface of cells, but in some cells preferentially accumulates in discrete microdomains of the plasma membrane. In polarized epithelial cells, NHE1 localizes to the basolateral membrane, in cardiac myocytes to intercalated disks and T-tubules and in resting fibroblasts to sites of focal adhesions. In contrast, in migrating fibroblasts, NHE1 concentrates at the leading edge of the cell along the border of lamellipodia. NHE1 abundance at the plasma membrane is regulated by its ubiquitination (Simonin and Fuster, 2010)

NHE1 serves as an important alkalinizing mechanism of the cell in defense of $\mathrm{H}^{+}$derived from metabolism or electrically-driven $\mathrm{H}^{+}$-accumulation. In addition, NHE1 constitutes a major pathway for $\mathrm{Na}^{+}$influx into the cell and when coupled to $\mathrm{Cl}^{-}$and $\mathrm{H}_{2} \mathrm{O}$ uptake, it represents a mechanisms for restoration of cell volume following cell shrinkage. In specialized secretory cell types like acinar cells of parotid or sublingual glands, NHE1 is necessary for secretagogue-induced fluid secretion. The unique subcellular localization of NHE1 in certain cell types suggests that NHE1 has additional biological functions. For instance, in cardiac myocytes, the specific localization of NHE1 to intercalated disks and Ttubules but not the peripheral sarcolemmal membranes is thought to affect local $\mathrm{pH}$, thereby influencing the activity of $\mathrm{pH}$-sensitive proteins, such as the gapjunction protein connexin 43 and the ryanodine-sensitive $\mathrm{Ca}^{2+}$ release channel. NHE1 is also involved in cell migration (Denker et al., 2000). Inhibition or genetic ablation of NHE1 in fibroblasts significantly reduces migration speed and deranges chemotaxis. Both ion translocation and anchoring of cytoskeletal proteins through the intracellular NHE1 C-terminus were shown to be necessary in this process. However, these effects appear to be cell specific; for instance, inhibition of NHE1 in granulocytes does not alter chemotaxis and chemokinesis (Hayashi et al., 2008). Furthermore, NHE1 knock-out mice exhibit normal embryogenesis (Bell et al., 1999; Cox et al., 1997).

The phenotype of two different $S / c 9 a 1$ knock-out mice has been reported. One is a spontaneous mutation ("swe" - slow-wave epilepsy) that arose in the Jackson laboratories which resulted in a truncation of the protein in the transmembrane domain with a subsequent NHE1-null phenotype (Cox et al., 1997). The second Slc9A1 knock-out was engineered by homologous recombination resulting in deletion of NHE1 transmembrane domains 6 and 7 (Bell et al., 1999). Loss of NHE1 was compatible with embryogenesis but knock-out mice exhibited a decreased rate of postnatal growth and high mortality with $\sim 10 \%$ of mice surviving at 5 weeks after birth (Bell et al., 1999). In addition, mice suffered from ataxia and epileptic seizures. This phenotype was associated with selective neuronal death in the cerebellum and brainstem of knock-out mice (Cox et al., 1997). Knock-out of Slc9A1 affected hippocampal and cortical cells by decreasing steady-state $\mathrm{pH}_{\mathrm{i}}$, attenuating $\mathrm{pH}_{\mathrm{i}}$ recovery from cell acidification (even in the presence of $\mathrm{HCO}_{3}^{-}$) and increasing expression and current density of voltage-gated $\mathrm{Na}^{+}$channels (Gu et al., 2001; Xia et al., 2003). Thus, loss of NHE1 seems to alter expression and activity of other membrane transport proteins in the brain, resulting in increased neuronal excitability.

Enhanced NHE1 activity can cause substantial intracellular $\mathrm{Na}^{+}$accumulation, that, through the activity of the plasmalemmal $\mathrm{Na}^{+} / \mathrm{Ca}^{2+}$ exchanger, induces a deleterious increase of intracellular $\mathrm{Ca}^{2+}$ that ultimately leads to cell death (Karmazyn, 1988). Genetic ablation 
pharmacologic inhibition of NHE1 during episodes of ischemia-reperfusion mitigated cardiac and neural injuries both in vivo and in vitro in rodents and pigs (Lazdunski et al., 1985), with the mechanism presumably being less $\mathrm{Na}^{+}$driven intracellular $\mathrm{Ca}^{2+}$ accumulation. Clinical trials in humans, however, have not been promising with no overall benefit of NHE1 inhibition by cariporide in acute coronary syndromes and no benefits in patients with acute myocardial infarction. NHE1 over-activity has also been linked to cardiac hypertrophy and heart failure. Wakabayashi developed a transgenic mouse that selectively overexpressed a constitutively active NHE1 in the heart (Nakamura et al., 2008). Increased NHE1 activity was sufficient to induce cardiac hypertrophy and ultimately heart failure in these transgenic mice.

The earliest evidence that NHE1 plays a role in the pathogenesis of cancer came from the studies of Pouyssegur and coworkers. In athymic nude mice, CCL39 hamster lung fibroblasts deficient in NHE1 caused tumors less frequently than wild-type cells with functional NHE1 (Lagarde et al., 1988). Since these initial observations, numerous studies have addressed the role of NHE1 in cancer. NHE1-dependent intracellular alkalinization seems to play an important role in the development of a transformed phenotype, which can be prevented by NHE1 inhibition (Reshkin et al., 2000b). In breast cancer and leukemic cells, inhibition of NHE1 exerts a protective effect against cancer, inducing apoptosis. In breast cancer cells, serum deprivation activates NHE1 to induce cell motility and invasion (Reshkin et al., 2000a). The protons extruded by NHE1 at the cell front create an acidic environment optimal for the activity of proteinases involved in the degradation of extracellular matrix. Low $\mathrm{pH}$ also enhances cell-matrix interactions and cell adhesion at the front. Thus, NHE1 seems to promote tumorigenesis at several levels, including cell proliferation, cell migration, invasion, metastasis and suppression of apoptosis. However, there is no evidence that inhibition of NHE1 is useful in treatment of cancer in humans.

NHE1 takes part in forming signaling complexes on its C-terminus (Baumgartner et al., 2004). NHE1 is regulated by phosphoinositides, postranslational modifications in the NHE1 C-terminus (phosphorylation, ubiquitylation) and binding proteins. The $\mathrm{Ca}^{2+}$-binding protein calmodulin was one of the first NHE1-binding proteins identified, and the crystal structure of the NHE1 - calmodulin complex was reported recently (Koester et al., 2011) Calmodulin binds to two sites in the NHE1 C-terminus: a high affinity site (amino acids 636-656) and a low affinity site (amino acids 657-700). In the absence of calmodulin, the high affinity binding site of NHE1 interacts with another region of NHE1, most likely the protonmodifier site in the transmembrane domain, acting in an autoinhibitory manner. In the presence of increased intracellular $\mathrm{Ca}^{2+}$ and calmodulin, this interaction is released and activation of NHE1 ensues. In support of this model, deletion of the calmodulin high affinity binding site on the NHE1 C-terminus renders NHE1 constitutively active.

Calcineurin homologous protein (CHPs 1-3) is another well studied NHE1-binding protein that was originally identified by screening an expression library with the NHE1 C-terminus. CHP1 is cytosolic, myristoylated and binds $\mathrm{Ca}^{2+}$ and interacts with a hydrophobic cluster of residues in the NHE1 proximal C-terminus located between amino acids 510 and 530. CHP1 is an obligatory binding partner of NHE1 (and also of NHE2 and NHE3). NHE1 or CHP1 mutants that interfere with the interaction result in a dramatic loss of NHE1 activity and NHE1 protein at the plasma membrane. CHP2 has $61 \%$ amino acid identity to CHP1 and binds to the same juxtamembranous region on the NHE1 C-terminus. CHP2 is highly expressed only in the intestine and in tumor cells and protects cells from serum deprivationinduced cell death by activating NHE1 and increasing cell $\mathrm{pH}$. The crystal structure of CHP2 in conjunction with the juxtamembranous portion of the NHE1 C-terminus was solved recently (Ben et al., 2005; Mishima et al., 2007). 
NHE1 transport requires ATP and cellular ATP depletion inhibits NHE1 activity. This is largely the result of cellular depletion of $\mathrm{PIP}_{2}$. As intracellular ATP levels fall, plasmalemmal $\mathrm{PIP}_{2}$ levels diminish concomitantly (Aharonovitz et al., 2000). Sequestration or hydrolysis of plasmalemmal PIP $_{2}$, in the absence of cellular ATP depletion, is associated with profound inhibition of NHE1 activity. In contrast, NHE1 function in ATP-depleted cells can be restored by direct perfusion of PIP 2 into the cell. NHE1 contains two C-terminal juxtamembrane stretches of positively charged amino acids that bind $\mathrm{PIP}_{2}$ in vitro (Aharonovitz et al., 2000). Mutation of these two sites greatly reduces NHE1 activity and $\mathrm{PIP}_{2}$ binding. The underlying mechanisms by which $\mathrm{PIP}_{2}$ affects NHE1 activity remain unknown. ATP, however, is also consumed during protein phosphorylation by kinases. Sardet et al. first demonstrated that NHE1 was a phosphoprotein (Sardet et al., 1990). Tryptic phosphopeptide mapping revealed that NHE1 was phosphorylated on serine and threonine but not tyrosine residues in response to growth factors. All relevant in vivo phosphorylation sites map to the NHE1 C-terminal 636-815 amino acids. However, deletion of these sites resulted in only a $\sim 50 \%$ loss of the growth factor stimulatory effect on NHE1 activity, suggesting that activation of NHE1 by growth factors occurs via additional mechanisms that do not require its direct phosphorylation. Kinases involved in NHE1 phosphorylation include: Calmodulin-dependent kinase II (CaM kinase II), extracellularregulated kinases 1 and 2 (ERK1/2), ribosomal protein S6 kinase (p90 RSK), p160ROCK, Nck-interacting kinase (NIK). Oppositely, dephosphorylation of NHE1 is carried out by protein phosphatases PP1 and PP2a, and prevention of de-phophosphorylation by inhibition of phosphatases maintains NHE1 in an active state.

A recently identified NHE1 splice variant is a $\mathrm{Na}^{+} / \mathrm{Li}^{+}$and not a $\mathrm{Na}^{+} / \mathrm{H}^{+}$exchanger. The functional relevance of this protein has not been established and NHA2 also carries out $\mathrm{Na}^{+} /$ $\mathrm{Li}^{+}$exchange.

\subsection{SIc9a2 - NHE2}

NHE2 is an epithelial Na $/ \mathrm{H}^{+}$exchanger, encoded by the $S L C 9 A 2$ gene, that has 812 amino acids and is in the brush border of the small intestine, colon and gallbladder but in the basolateral membrane of stomach and is also in endothelial cells where it contributes to forming the blood brain barrier (Tse et al., 1993; Wang et al., 1993; Hoogerwerf et al., 1996). It is present in the kidney, in the apical domain of the thick ascending limb of Henle and the distal convoluted tubules.

Physiologically, the functional role of NHE2 is not established, although it is involved in some intestinal and renal $\mathrm{Na}$ absorption and there is recent evidence that it has a role in repair of epithelial damage (Xue et al., 2011). In cell systems, it is primarily present in the brush border, is not regulated by trafficking except potentially for its stimulation by short chain fatty acids, and unlike NHE3 its activity is not PI 3-kinase dependent. The location of NHE2 is in the brush border (BB) of villous cells and upper crypt cells of human small intestine and surface cells of the proximal and distal colon and sigmoid with its major expression in the distal colon. In the mouse colon, it is also in the crypt cell BB. SIc9a2 KO mice have no intestinal phenotype with $S / c 9 a 3 / S / c 9 a 2$ double knock out being similar to Slc9a3 KO. The contribution of NHE2 to intestinal $\mathrm{Na}^{+} / \mathrm{H}^{+}$exchange activity varies based on species. In rabbit ileum, half of NHE activity is due to both NHE3 and NHE2; in rat small intestine, NHE2 only accounts for $1 / 3$ of the NHE activity and NHE2 does not contribute to canine ileal basal or post-prandial Na absorption. Similarly, NHE2 contributes only $10 \%$ to rat proximal colon NHE activity, and 25\% to distal colon (Hoogerwerf et al., 1996), but it accounts for almost all chicken colonic NHE activity. Acute NHE2 regulation has not been thoroughly studied, although in Caco-2 cells, NHE2 is inhibited by cAMP and elevated $\mathrm{Ca}^{2+}$ (including by serotonin), stimulated by serum and not affected by cGMP and PKC; results in response to hyperosmolarity are contradictory with both inhibition and 
stimulation reported. In a model of enteropathogenic E. coli (EPEC) related diarrhea in Caco-2 cells, NHE2 was inhibited and NHE2 is also inhibited by cholera toxin in rat ileum (Hecht et al., 2004). In colon NHE2 is linked to a short chain fatty acid/ $\mathrm{HCO}_{3}$ exchanger which is inhibited by cAMP but the inhibition is reversed by luminal butyrate (Subramanya et al., 2007). It is possible that the role of NHE2 in epithelial repair is a major function. Parietal cells are missing in $S / c 9 \mathrm{a} 2 \mathrm{KO}$ mice consistent with NHE2 being involved in preventing or responding to damage (Schultheis et al., 1998a,b). In mouse intestine, the presence of NHE2 increased recovery in ischemia related altered tight junction function and in mouse gastric epithelium, recovery from damage was NHE2 dependent, including that mediated by Trefoil factor 2 (Xue et al., 2011). There are no structural studies of NHE2 and no diseases described caused by its defective function. In $5 / c 9 \mathrm{a} 2 \mathrm{KO}$ mice, there is increased renal renin content, even though the animals do not appear to be dehydrated. This suggests a role for NHE2 in signal transduction regulating renin expression.

\subsection{SIc9a3 - NHE3}

NHE3, which contains 834 amino acids in man (Brant et al., 1995), is encoded by the $S L C 9 A 3$ gene and is an example of the NHE isoforms which continually traffick between the recycling system and the plasma membrane with their major function being in the plasma membrane (Janecki et al., 1998; Chow et al., 1999). NHE3 is thus most related to NHE5 and dissimilar to the intraorganellar NHEs which oppositely have their major function in the organellar membranes (Brett et al., 2005a). NHE3 is present in the $\mathrm{Na}$ absorptive cells of the mammalian small intestine, colon, gall bladder, renal proximal tubule, and thick and thin limbs of the loop of Henle (Hoogerwerf et al., 1996). It is present in gastric parietal cells either on the basolateral membrane (BLM) or apically based on species. It is also present in the epididymis, ovary, thymus, prostate, in some respiratory neurons in the ventrolateral medulla oblongata and in the most rostral extension of the retrotrapezoid nucleus/parapyramidal region in the pons. NHE3 is responsible for the majority of intestinal and renal $\mathrm{Na}$ absorption taking part in proximal, low efficiency-high capacity systems called neutral $\mathrm{NaCl}$ absorption (Zachos et al., 2005). In this process, NHE3 is linked to members of the SLC26A family of $\mathrm{Cl} / \mathrm{HCO}_{3}$ exchangers, particularly DRA (SLC26A3) and to an unclear extent PAT-1 (SLC26A6) as well (Jacob et al., 2002). The linkage is indirect via changes in pHi but since both NHE3 and DRA bind multiple members of the NHERF family of multiple PDZ domain proteins, potentially via the physical linkage of NHE3 and DRA as well. In intestinal $\mathrm{Na}$ absorptive cells, nutrient (D-glucose and $\mathrm{D}$-galactose, $\mathrm{L}$-amino acid) related $\mathrm{Na}$ absorption and neutral $\mathrm{NaCl}$ absorption had been thought to be independent processes (Zachos et al., 2005). However, it is now known that o-glucose, acting via SGLT1 (SLC5A1), increases NHE3 trafficking to the BB of intestinal Na absorptive cells (Turner and Black, 2001; Lin et al., 2011). In this, SGLT1 uptake of D-Glu initiates an apical signaling cascade that includes p38 MAP kinase, MAP kinase kinase, PI3-K, AKT2, ezrin, and NHERF2 to increase NHE3 exocytosis. This linkage, along with changes in tight junctional permeability, is likely to contribute to the stoichiometry of $\mathrm{Na}$ to glucose absorption seen with oral rehydration solution (ORS) being higher than that of SGLT1 (2 $\mathrm{Na}: 1$ o-glu). Importantly, the ${ }_{\mathrm{D}}$-glucose stimulation of NHE3 reversed cholera toxin inhibition of NHE3 indicating that treatment of acute diarrhea could use ORS reversal of NHE3 inhibition to allow NHE3 to be a drug target for further stimulation of NHE3 activity (Lin et al., 2011). In the intestine, NHE3 regulation occurs acutely as part of digestion, and in the kidney changes occur largely as part of total body volume homeostasis. The time frame of regulation appears to be faster as part of digestion, although short term, intermediate and long term regulation occurs in both intestine and kidney. In the intestine, NHE3 is inhibited in the immediate post-prandial period, which probably helps to spread the digestive enzymes over the digestive/absorptive surface as part of the digestive process. 
Later in digestion, there is stimulation of NHE3 which probably helps prevent dehydration as part of digestion.

The involvement of NHE3 in respiration is not well defined but inhibiting NHE3 seems to lower the apneic threshold and activates the central respiratory response to $\mathrm{CO}_{2}$, while increasing expression lowers the respiratory drive (Wiemann et al., 1999).

NHE3 trafficks between the brush border and recycling system and in the latter contributes to acidification. How this function interacts with the organellar V-ATPase is not known.

NHE3 is one of the most regulated of transport proteins with regulation occurring acutely, as well as on both an intermediate and long term basis including circadian regulation (Donowitz and Li, 2007). Rat colonic NHE3 undergoes diurnal variation which is maximum at midnight, a time of rodent eating (Sotak M. et al., 2011). Detailed reviews of second messenger and ligand regulation of NHE3 have been reported (Zachos et al., 2005; Donowitz and Li, 2007; Bobulescu and Moe, 2006). Acute regulation largely occurs by changes in rates of endocytosis and exocytosis which set the percent of NHE3 on the plasma membrane under basal conditions, although changes in NHE3 plasma membrane half-life have been documented. Of note, changes in the $\mathrm{K}^{\prime}\left(\mathrm{H}^{+}\right)_{i}$ occur as well with acute changes in NHE3 activity, either alone or as part of NHE3 regulation as part of changes in trafficking. Endocytosis of NHE3 occurs by clathrin, lipid raft, and CDC42 dependent mechanisms, although why there is such complexity is not understood (Chow et al., 1999; Janecki et al., 1998; Li et al., 2001; Zachos et al., 2009). An additional aspect of acute regulation of NHE3 was recently defined in epithelial cells as a component of acute NHE3 stimulation and inhibition by changes in trafficking. This appears to have developed to deal with NHE3 being fixed to the microvillar cytoskeleton under basal conditions, which occurs via linking of NHE3 to the microvillar actin cytoskeleton by direct binding to ezrin plus by indirect binding to ezrin which occurs by ezrin binding to NHERF1 and NHERF2, with the latter two being NHE3 binding proteins. Acute stimulation of NHE3 by D-glucose and LPA and inhibition by elevated intracellular $\mathrm{Ca}^{2+}$ and cAMP are associated with dynamic and transient increased mobility in the microvillus of NHE3 which correlates with reduced binding to NHERF2 but not NHERF1 (Lin et al., 2011; Zhu et al., 2011). This dynamic association of NHE3 with the microvillar cytoskeleton allows NHE3 that is delivered to the $\mathrm{BB}$ as part of stimulated exocytosis to be spread over the microvillus; and also to gather microvillar NHE3 to take part in stimulated endocytosis.

The NHE3 C-terminus is necessary for its regulation. In this regulation, the NHE3 Cterminus acts as a scaffold binding multiple proteins and phosphoinositides that regulate it. To date the NHE3 regulatory proteins and lipids which directly bind the NHE3 C-terminus include CHP, ezrin, PIP2 and PIP3, CaMKII, CaM, PLC, IRBIT, megalin (Donowitz et al., 2009; He et al., 2008). The number of NHE3 associating proteins is almost certainly to have been only partially defined, given that the size of NHE3 complexes based on 5-60\% sucrose density gradients is 1000-2000 kDa. Two major signaling complexes in the NHE3 Cterminus have been identified, both of which form at the sites at which NHE3 associates with the actin cytoskeleton, one the site of direct ezrin binding which appears involved in stimulation of NHE3 activity, and one at the site of the binding to the cytoskeleton via ezrin which occurs by ezrin-NHERF 1 or 2 binding, which is involved primarily in inhibition of NHE3 activity (Donowitz et al., 2008; Cha et al., 2006). The major NHE3 signaling complex defined till now appears involved in the post-prandial inhibition of NHE3 activity, which appears to be the major function of NHE3 in the intestine. This complex includes NHERF1-4, two kinases, one of which stimulates NHE3 (CK2) and one of which inhibits NHE3 (CaMKII) under basal conditions, PLC and potentially IRBIT and CaM. Multiple other protein-protein interactions affect NHE3 activity (for example, BetaPix-Shank2; 
DPPIV) (Girardi et al., 2001; Lee et al., 2010). The complexity of NHE3 regulation in the apical domain is indicated by multiple pools of NHE3 being identified in both the brush border and intracellularly. These have been defined in multiple ways and the degree of overlap is largely unknown: brush border NHE3 is partially in lipid rafts, but also in a detergent soluble pool, partially bound to megalin, active or inactive, immobile (bound to NHERF proteins; separately Rho GTPase dependent) or easily mobilized (bound to NHERF2) and affected by changes in membrane curvature; while part of intracellular NHE3 is active and part can be divided into that rapidly or more slowly able to be mobilized for stimulated exocytosis (Alexander et al., 2007). The cytoskeleton is involved in NHE3 regulation in multiple ways. In epithelial cells, NHE3 is fixed to the microvillar actin cytoskeleton dynamically via direct and indirect binding to ezrin as described above. For trafficking in epithelial cells, endo and exocytosis of NHE3 must move NHE3 through the actin mesh in the terminal web (larger in intestinal than renal epithelial cells), an affect which involves myosin VI. Clostridium difficile toxin B dissociates NHE3 from the epithelial cell actin cytoskeleton and leads to its internalization as does inhibition of Rhokinase, while in non-polarized cells, the actin cytoskeleton is necessary for basal NHE3 activity, by affecting turnover number, and cytoskeletal reorganization appears to be needed for non-trafficking related inhibition by cAMP elevation (Hayashi et al., 2004).

The $\sim 377$ aa C-terminus of NHE3 is predicted to have a structure with multiple helical domains predicted in the domains closest to the $\mathrm{N}$-terminal transport domain. One of these domains, NHE3 amino acids 473-497 is highly homologous to a domain in the NHE1 Cterminus (amino acids 516-540) for which the structure has been solved when bound to CHP2 (calcineurin homologous protein) (Ammar et al., 2006). This domain is a-helical and is intimately intertwined with CHP.

Linkage of $S L C 9 A 3$ to human diseases is limited, although animal models suggest likely clinical implications. SIc9a3 KO mice have mild diarrhea, increased water in the intestinal lumen and markedly increased mortality when placed on a low Na diet (Schultheis et al., 1998a,b). While the blood pressure of these mice is reduced, it can be normalized by increasing dietary Na content. A distal colitis has been identified in Slc9a3 null mice (Woo et al., 2002). This was not seen by the group which produced this mouse but was identified when the same mouse was housed in a different institution. This strongly suggests involvement of changes in the intestinal microbiome. INF was increased in small intestine but not colon of NHE3 null mice, without distal colitis. In contrast, in mice with the NHE3 null related colitis, there was increased severity of DSS induced colitis and appearance of a small intestinal enteritis which is not seen as part of DSS colitis in wild type mice (Kiela et al., 2009). In these mice, oral antibiotics reduced INF expression to basal levels and delayed some of the increased mortality from DSS, again supporting the role of the microbiome in the increased intestinal inflammation seen in the absence of NHE3. While absence of NHE3 influences inflammation and the inflammatory response in the intestine, intestinal inflammation also seems to alter NHE3 activity. NHE3 activity was reduced in the colonic crypts of patients with ulcerative colitis. Concerning mechanism of this reduced NHE3 activity, NHE3 is one of multiple intestinal transport proteins and their regulators which are down regulated in IBD, although there is controversy about whether this is due to changes in mRNA or protein or regulation involving changes in turnover number. In sigmoid colonic biopsies from patients with Crohn's disease and ulcerative colitis, based on immunoblotting, there was decreased amounts of NHE3 (as well as NHE1, -ENaC, NHERF1, CLC-5 and NaK-ATPasae subunit) and in mouse colon from DSS and TNBS-colitis there was reduced NHE3 (and NHE1, -ENaC and NHERF1 and NHERF2)(Sullivan et al., 2009). However, SLC9A3 mRNA in patients with ulcerative colitis, in spite of reduced NHE3 activity, was unchanged compared to controls (Yeruva et al., 2010). In addition based on immunofluorescence studies, there was no change in amount or distribution of NHE3 in 
sigmoid colonic biopsies of patients with ulcerative colitis. Thus, the mechanism of the inflammation induced inhibition of NHE3 activity in IBD remains controversial. However, similarly to IBD, EPEC (enteropathogenic E. coli related) diarrhea, which causes small intestinal inflammation, was associated with reduced NHE3 (but increased NHE2 and NHE1) activity (Hecht et al., 2004). The EPEC inhibition of NHE3 required the bacteria's type three secretion system and the bacterial virulence factor EspF, although how they contribute to the pathophysiology is not known.

The suggestion has been made, although without strong supporting data, that sudden infant death syndrome is associated with increased brainstem expression of NHE3. This is suggested to lead to a reduced respiratory drive. There was increased frequency of sudden infant death syndrome associated with the R799C NHE3 polymorphism as well as with two SLC9A3 promoter polymorphisms (G1131A and C1197T), although the study was criticized since controls were not age matched (Poetsch et al., 2010).

\subsection{SIc9a4 - NHE4}

Human NHE4 has 798 amino acids and is encoded by the SLC9A4 gene. The expression of NHE4 is highest in stomach and is also found although at lower levels in kidney medulla, hippocampus, zymogen granule of pancreas, and salivary gland. NHE4 localizes to the basolateral membrane of epithelial cells in these tissues where NHE1 also resides. In stomach, NHE4 is expressed in parietal cells. In kidney, NHE4 is found in macula densa cells, thick ascending limb and distal convoluted tubule, and to a lesser extent in collecting ducts and proximal tubules. In salivary gland, NHE4 is expressed in acinar and duct cells. However, NHE4 is not found in small and large intestine. When expressed in fibroblasts, NHE4 is virtually inactive but can be activated by cell shrinkage or by $4,4^{\prime}$ diisothiocyanostilbene-2, $2^{\prime}$-disulfonic acid, an anion transporter inhibitor (Chambrey et al., 1997). NHE4 is relatively resistant to amiloride and its analogs.

The physiological function of NHE4 is not clear, although NHE4 knock-out mice have provided some insight into its physiological functions (Bourgeois et al., 2010;Gawenis et al., 2005). NHE4 does not appear to be involved in $\mathrm{pH}$ regulation of epithelial cells. In GI tract, Slc $9 a 4$ (-/-) mice are hypochlorhydric. Histological studies indicate that $S / c 9_{a} 4(-/-)$ mice have reduced numbers of parietal cells, loss of mature chief cells; and increased number of undifferentiated cells as well as necrotic and apoptotic cells (Gawenis et al., 2005). Slc9a4 $(-/-)$ parietal cells exhibit limited development of canalicular membranes and absence of tubulovesicles. Gawenis et al. suggest that basolateral NHE4 in parietal cells, functionally coupled with anion exchanger-2 (AE2, SLC4A2) is important for maintaining cell volume and intracellular ion concentrations for acid secretion (Gawenis et al., 2005). Slc4a2 knockout mice are also achlorhydric (Gawenis et al., 2004). Consistent with this hypothesis, the cell volume of parietal cells from Slc9a4 (-l-) mice is reduced. In kidney, NHE4 is critical for $\mathrm{NH}_{4}{ }^{+} / \mathrm{NH}^{3}$ absorption in medullary thick ascending limb of Henle's loop (TAL) where the apical $\mathrm{Na} / \mathrm{K} / 2 \mathrm{Cl}$ contransporter (NKCC2, SLC12A1) is responsible for $\mathrm{NH}_{4}{ }^{+}$absorption and the basolateral NHE4 is responsible for its exit (Eladari and Chambrey, 2010). This is supported by the observation that purified TAL basolateral membrane vesicles exhibit NHE activity which can function as a $\mathrm{Na} / \mathrm{NH}_{4}{ }^{+}$exchanger. Some of the ammonia that the TAL reabsorbs undergoes recycling by the descending thin limb of Henle's loop (DTL), and the continuing $\mathrm{NH}_{4}+/ \mathrm{NH}_{3}$ absorption and secretion by TAL and DTL, respectively, results in accumulation of ammonia in medullary interstitium (Eladari and Chambrey, 2010). This provides an effective gradient for ammonia excretion in distal tubule. Thus, when challenged with oral acid load, Slc9a4 (-/-) mice are unable to increase their urinary ammonium and net acid excretion and the lack of NHE4 prevents the medullary ammonia accumulation, resulting in metabolic acidosis and failure to increase urinary ammonium excretion. During chronic metabolic acidosis, NHE4 expression and activity are adaptively 
increased in response to the increased demand for urinary excretion of $\mathrm{NH}_{4}{ }^{+} / \mathrm{NH}_{3}$ (Bourgeois et al., 2010).

\subsection{SLC9A5 - NHE5}

Human NHE5 is encoded by the $S L C 9 A 5$ gene, has 896 amino acids and its expression is highly restricted to brain and sperm. It is found in multiple regions of the brain including the dentate gyrus, cerebral cortex, hippocampus, amygdala, caudate nucleus, hypothalamus, subthalamic nucleus, and thalamus but not in glia-enriched structures such as the corpus callosum, suggesting that NHE5 might be neuron-specific. It has highest homology with NHE3 with about $50 \%$ in amino acid identity and shares similar pharmacological, regulatory and cell localization properties. Thus, NHE5 is located at both plasma membrane and recycling endosomes when expressed in mammalian cells and cycles between these two pools. The internalization of NHE5 is clathrin-mediated and forms a complex with $\beta$ arrestins (Lukashova et al., 2011;Szabo et al., 2005). $\beta$-arrestin- 2 directly binds to the ser/ thr-rich, di-isoleucine motif region in the C-terminus of NHE5 (amino acid 697-723) which is robustly phosphorylated by CK2 (Lukashova et al., 2011). Simultaneous mutation of the five Ser/Thr residues to Ala within NHE5 amino acids 702-714 abolished phosphorylation and binding of $\beta$-arrestin- 2 in vitro. However, this mutant retained its ability to form a complex with $\beta$-arrestin-2 in vivo despite its lack of responsiveness. Additional mutations of two di-isoleucine-based motifs (I697A/L698A and I722A/I723A), either independently or together, disrupt this interaction. Thus, phosphorylation of NHE5 by CK2 is required for binding to $\beta$-arrestin-2 and for internationalization of NHE5 to recycling endosomes (Lukashova et al., 2011). On the other hand, the secretory carrier membrane protein, SCAMP2 shuttles NHE5 to the cell surface (Diering et al., 2009). SCAMP2 binds to NHE5 via both of its $\mathrm{N}$ - and $\mathrm{C}$-terminal cytosolic domains and co-localizes with NHE5 predominantly in the recycling endosomes. Heterologous expression of SCAMP2 increases cell-surface abundance of NHE5 without affecting NHE5 internalization. Expression of a deletion mutant lacking the SCAMP2-specific $\mathrm{N}$-terminal cytosolic domain or $\mathrm{N}$-terminal cytosolic domain of SCAMP2 (amino acid 1-154) reduce the transporter activity. The small GTPases Arf6 and Rab11 regulate membrane traffic of NHE5 from recycling endosomes to the cell surface. The SCAMP2- mediated surface targeting of NHE5 is Arf6, but not Rab11 dependent. The dynamic distribution of NHE5 between plasma membrane and recycling endosomes is controlled by PI 3-K (exocytosis) and by the state of F-actin assembly (endocytosis). In addition to $\beta$-arrestins and SCAMP2, the $\mathrm{N}$-terminus of receptor for activated C-kinase 1 (RACK1) directly binds to the C-terminus of NHE5 and positively regulates the transporter function (Onishi et al., 2007). RACK1 is a PKC interacting protein and scaffold protein that contains seven Trp-Asp (WD) repeats, each of which could independently interacts with other proteins. NHE5 co-localizes with RACK1, $\beta 1$ integrin, paxillin and vinculin, markers of focal adhesions. Upon cell spreading which activates integrin-mediated signaling, RACK1 is recruited to the NHE5-integrin complex and perhaps stabilizes the complex. Knocking down RACK1 not only reverses integrin effects but also further lowers NHE5 activity. Thus, RACK1 regulates NHE5 via both integrin-dependent, and independent pathways. NHE5 might also be regulated by other kinases since in heterogonous expression of NHE5 in PS120 fibroblasts, NHE5 can be inhibited by protein kinase A, protein kinase C and hyperosmolarity (Attaphitaya et al., 2001).

The physiological functions of NHE5 were not known until recently. Numata et al. demonstrated that NHE5 acts as a negative regulator of dendritic spine growth which depends on NHE5 specific activity that regulates synaptic cleft pH (Diering et al., 2011). Enhanced neuronal activity targets NHE5 from endosomes to plasma membranes of dendritic spines. The increased activity of NHE5 results in alkalinization of the dendritic spine and concomitant acidification of the synaptic cleft. This local acidification may serve 
as an autocrine feedback mechanism that regulates $\mathrm{pH}$-sensitive proteins at the postsynapse such as $N$-methyl $D$-aspartate receptors and possibly also as a paracrine mechanism to regulate presynaptic $\mathrm{pH}$-sensitive proteins such as voltage gated $\mathrm{Cl}$ channels.

Overexpression of NHE5 blocks spine growth in response to neuronal activity. Knockdown of $S l c 9 a 5$, or expression of a dominant-negative Slc9a5 mutant (E209 mutant), results in spontaneous spine outgrowth. It is therefore suggested that NHE5 controls dendritic spine growth via a pH-dependent negative-feedback mechanism (Diering et al., 2011).

\subsection{SLC9A6, SLC9A7 and SLC9A9 - Intracellular NHEs: NHE6, NHE7, NHE9}

Nhx1, NHE6, NHE7, NHE9 are considered together as intracellular members of the NHE family derived evolutionarily from the $S$. cerveciae Nhx1, the first member of this family molecularly identified (Nass et al., 1997). Nhx1 is probably a model for the function of the other intracellular NHEs, and is a $\mathrm{K}^{+}$and $\mathrm{Na}^{+} / \mathrm{H}^{+}$antiporter, that is present in the yeast vacuolar membrane where it serves to exchange intra vacuolar $\mathrm{H}^{+}$for cytosolic $\mathrm{K}^{+}$and thus sets the vacuolar and cytosolic $\mathrm{pH}$ and also appears to be involved in trafficking/fusion from the late endosome to the vacuole (Brett et al., 2005b). Nhx1 appears to control both early steps of membrane trafficking from the late endosome to vacuole and fusion in the vacuole, effects dependent on intravacuolar $\mathrm{pH}$. Abnormalities in these steps due to Nhx1 KO could be reversed by correcting the vacuolar $\mathrm{pH}$. In a cell free system, Nhx 1 was necessary for formation of multivesicular bodies acting to recruit Vps27, an ESCRT protein, to the endosomal membrane. While these results support the role of NHX1 as part of the ESCRT sorting pathway, a recent study showed, Nhx1 was not necessary for multivesicular body formation, and suggested that Nhx1 serves a role in endosomal membrane fusion downstream of the ESCRT pathway (Kallay L.M. et al., 2011).

NHE 6,7,9, encoded by the $S L C 9 A 6, S L C 9 A 7$ and $S L C 9 A 9$ genes respectively, appear to have different localizations in intracellular organelles primarily along the endosomal and secretory pathways (Nakamura et al., 2005; Ohgaki et al., 2011); however, it is not known whether this is somewhat dependent on the functional state of the cell. The functions of these NHEs is thought mostly to set intraorganellar pHs at lesser acidity that generated by the V-ATPase in the organellar membranes with which they function in parallel; whether the functions of these NHEs are redundant is unclear. NHE6 is mostly considered a recycling endosomal protein (Brett et al., 2002), NHE7 trans-Golgi (Numata and Orlowski, 2001) and NHE9 late and recycling endosomes and late endosomes/lysosomes (Nakamura et al., 2005). NHE8 (encoded by SLC9A8), which is discussed separately, is present in mid to transGolgi, although it appears to be present in the BB of some epithelial cells. The basis for thinking these NHEs control organellar $\mathrm{pH}$ is that overexpression of each increased the intraorganellar $\mathrm{pH}$ in which they were primarily expressed (Nakamura et al., 2005). While these NHEs are present primarily in intracellular organellar membranes, in some cells they are present in other locations; for instance in vestibular hair bundles, NHE9 and less consistently NHE6 are present in the plasma membrane where they serve to remove cytosolic $\mathrm{H}^{+}$in exchange for endolymph $\mathrm{K}^{+}$(Hill et al., 2006). Tissue distribution of these NHEs is ubiquitous only for NHE9, with increased expression of NHE6 in brain and NHE7 in brain and skeletal muscle. Functionally the organellar NHEs exchange $\mathrm{Na}^{+}$or $\mathrm{K}^{+}$for intraorganellar $\mathrm{H}^{+}$(in contrast to the plasma membrane NHEs which primarily exchange $\mathrm{Na}^{+}$for $\mathrm{H}^{+}$). It has been suggested that this difference in cation selectivity may be related to the presence of multiple charged residues at the putative second extracellular loop. The intraorganellar NHEs have similar Vmax and $\mathrm{Km}$ for $\mathrm{Na}^{+}$and $\mathrm{K}^{+}$.

NHE6, is present primarily in the recycling endosomes but a minor component is also present in the plasma membrane, for instance in vestibular hair bundles, adipocytes, fibroblasts and likely many other cells and it has a major plasma membrane distribution in a few specialized cells; for instance in the basolateral membrane of osteoblasts, particularly in 
areas of high mineralization, where it helps to remove the high $\mathrm{H}^{+}$load produced by mineralization. Another function of NHE6 was demonstrated in hepatoma HepG2 cells which express a splice variant of Slc9a6 (NHE6.1). Knock down of NHE6.1 lowered recycling endosomal $\mathrm{pH}$ and surprisingly disrupted the apical canalicular plasma membrane including failure to traffick or maintain apical proteins; these effects were associated with reduced amounts of apical lipids and suggests an effect of NHE6 in regulating apical recycling that involves lipids as well as proteins. However, in other cell models, knocking down NHE6 did not alter endosomal pH while knocking down NHE9 in addition did lead to acidification of early endosomes, suggesting either was sufficient for the $\mathrm{pH}$ regulation. In addition, based on knock down studies, NHE6 has a role in clathrin dependent endocytosis in HeLa cells by acidifying clathrin containing endocytic vesicles; NHE6 co-localizes with clathrin and knocking it down inhibits early steps in transferrin endocytosis but not that of substrates endocytosed by non-clathrin dependent mechanisms (cholera toxin B subunit and EGF) (Xinhan L. et al., 2011).

Regulation of the intracellular NHEs has been incompletely studied. However, NHE6 (as well as NHE7 and 9) bind RACK1, using the NHE cytoplasmic C-terminus. Knocking down RACK1 led to more intracellular and less plasma membrane NHE6 and was accompanied by higher $\mathrm{pH}$ in the recycling endosomes (Ohgaki et al., 2008). This suggests there is regulated trafficking of NHE6 between the plasma membrane and recycling endosomes that is RACK1 dependent and that this balance affects the intracellular $\mathrm{pH}$ of the recycling endosome.

NHE6 and NHE7 have multiple additional C-terminal binding partners (cytosolic proteins); however, the functions of which relating to regulation of these NHEs are poorly understood. NHE7 binds SCAMPS, involved in vesicle trafficking, calmodulin which binds multiple other plasma membrane NHEs, caveolin, CD44, and most intriugingly GLUT1 (Lin et al., 2005; Kagami et al., 2008). This is another area in which these NHEs are similar to plasma membrane NHEs, especially NHE1, NHE3 and NHE5, with identification of the binding partners of the intraorganellar NHEs just beginning.

NHE7 appears to be the NHE isoform present in the trans-Golgi, although it also trafficks to the recycling system and to the plasma membrane (Numata and Orlowski, 2001). As with other NHEs, it is partially localized to lipid rafts and associates with caveolin. The NHE7 Cterminus was responsible for its trans-Golgi localization compared to NHE6, but NHE6 localization to the recycling system could not be attributed to the NHE6 C-terminus. An unusual feature of NHE7 is its insensitivity to amiloride, while it is inhibited by benzamil and quinine.

Diseases of the intracellular NHEs: in keeping with importance of maintenance of organellar $\mathrm{pH}$, multiple neurological syndromes have been associated with consequences of disrupting functions of the intracellular NHEs, particularly NHE6 and NHE9 (Morrow et al., 2008; Gilfillan et al., 2008; Takahashi et al., 2011; Yasuda et al., 2011; Roxrud et al., 2009). The specific associations include: SLC9A9: mutations are possibly involved in familial autism although some studies did not find an association and there is also a possible association with attention deficit hyperactivity disorder; SLC9A6: multiple cases of X-linked mental retardation resembling Angelman syndrome and Christianson sub type have had truncation, deletion, point mutations and exon skipping of NHE6. While expressed in neurologic tissues in significant amounts, how mutations in $S L C 9 A 6$ and $S L C 9 A 9$ lead to neurologic disorders is not known, although it has been suggested that these mutations lead to failure to establish normal polarity or that the mutations altered vesicle trafficking by altering cytoskeleton interactions of NHE6. 


\subsection{SLC9A8 -NHE8}

The $S L C 9 A 8$ gene encodes human NHE8 which has 581 amino acids, and its message is ubiquitously expressed in mouse and human tissues with highest expression in skeletal muscle and kidney. From a phylogenetic analysis of mammalian SLC9s, SLC9A8 was predicted to encode an intracellular NHE and shares about 25\% homology with other members of the gene family (Brett et al., 2005a). Furthermore, the C-terminus of NHE8 is 50-100 amino acids shorter than other NHEs and shares no significant amino acid similarity, suggesting that the regulation of NHE8 is different from other members. Indeed, NHE8 is an intracellular NHE in mosquito Malpighian tubules (Kang'ethe et al., 2007). When expressed in mammalian $\mathrm{CHO}$ and HeLa cells, it is localized primarily to mid- to trans-Golgi and to a lesser extent to endosomes (Nakamura et al., 2005). Silencing NHE8 in HeLa-M cells results in perinuclear clustering of endosomes and lysosomes and perturbs endosomal protein trafficking. Bowers et al. suggest that NHE8 might be a negative regulator of inward vesiculation or NHE8 might promote back fusion (Lawrence et al., 2010). These processes are driven by endosomal $\mathrm{pH}$, the steady-state of which is maintained by vacuolar ATPase and intracellular organelle NHEs (Lawrence et al., 2010).

In addition to its intracellular location, NHE8 is localized to the apical membrane of renal proximal tubule and intestine. In kidney, NHE8 is restricted to the proximal tubules whereas in intestine, NHE8 is found in stomach, duodenum, jejunum, ileum and colon. Both NHE3 and NHE8 are developmentally regulated with NHE8 being the major intestinal brush border NHE in neonates and NHE3 being the predominant brush border NHE in adults (Xu et al., 2008; Becker et al., 2007). In neonatal rat proximal tubules, there is considerably NHE activity despite the amount of NHE3 protein being low. The presence of NHE activity in proximal tubules of $S / c 9 a 2 / S I c 9$ a3 double knock-out mice raised the possibility of the presence of an additional brush border NHE other than NHE2 and NHE3 which mediates renal acidification (Choi et al., 2000; Xu et al., 2011). There appears to be compensatory upregulation of intestinal NHE8 in Slc9a2/SIc9a3 double knock-out mice and this upregulation of NHE8 appears to be gender dependent (Xu et al., 2011). The signal for the developmental NHE expression switch is unclear but is coincident with perinatal increase in serum glucocorticoids and thyroid hormones. Baum et al. demonstrated that the abundance of NHE3 protein and message in renal proximal tubules of neonatal animals can be increased by administering either glucocorticoids or thyroid hormones. Alternatively, administration of thyroid hormone to neonates before the normal increase that occurs at weaning results in a premature decrease in brush border NHE8 protein abundance. Conversely, high levels of brush border NHE8 persist into adulthood in hypothyroid rats (Gattineni et al., 2008). Similarly, the expression of Slc $9 a 8$ mRNA and protein in intestine is decreased in glucocorticoid-treated animals whereas SIc9a3 mRNA and protein are upregulated (Xu et al., 2010).

Although NHE3 is the major renal and intestinal brush border NHE in adults, NHE8 appears also to contribute to $\mathrm{Na}$ absorption in these adult tissues although results are not definitive. Decreased expression of NHE8 protein and message is associated with defective acidification in proximal convoluted tubules of aged rats (Fiori et al., 2009). In intestinal inflammation, both NHE3 and NHE8 are decreased, accounting for reduction of Na absorption in inflammatory diarrhea. Somatostatin stimulates NHE8 but not NHE3 expression in the mouse intestine (Wang et al., 2011). While brush border NHE activity is decreased in patients with congenial Na diarrhea, there is no identified exonic mutation in $S L C 9 A 3$ or $S L C 9 A 8$ in these patients (same for SLC9A1/2/5) leaving the inhibited NHE activity in this condition not understood (Baum et al., 2011).

Is NHE8 an intracellular NHE or a plasma membrane NHE? Expression of exogenous NHE8 in CHO and HeLa cells results in intracellular localization but its expression in 
PS120 fibroblasts allows sufficient amount of surface NHE8 protein for functional characterization (Xu et al., 2008), In rat renal proximal tubules, the brush border NHE8 protein decreases upon maturation but the total amount of NHE8 in renal cortical membranes is higher in the adult compared to the neonate and there is no change in the amount of Slc9a8 message (Becker et al., 2007). These findings suggest that a substantial amount of NHE8 is intracellular in adult proximal tubules. Immunostaining of adult proximal tubules with NHE8 antibodies also shows that it is in the coated pit regions in addition to brush borders (Goyal et al., 2005). Therefore, while NHE8 resides on the brush border of intestine and renal proximal tubules in neonates, it is predominantly intracellular upon maturation of animals, at least in renal proximal tubules. What governs the steady-state plasma membrane and intracellular expression of NHE8 remains to be determined.

\section{SLC9B/NHA family}

The SLC9B exchangers have recently been added to the SLC9 family. Brett and coworkers used a bioinformatics approach to identify a previously unrecognized family of NHEs that were present in all completely sequenced metozoan genomes (Brett et al., 2005a,b). Compared to NHE isoforms 1-9, these newly identified NHEs had higher homology to prokaryotic NHEs, like the E.coli NhaA, and were thus named NHA1 (encoded by SLC9B1; also called NHEDC1) and NHA2 (encoded by $S L C 9 B 2$; also called NHEDC2), respectively. In the species-independent monovalent cation/proton antiporter (CPA) classification, NHA1 and NHA2 belong to the CPA2 family. NHAs are predicted to contain 12 transmembrane domains, but unlike NHEs1-9, seem to possess only short intracellular N- and C-termini.

The 515 amino acid long NHA1 was cloned in 2006 (Ye et al., 2006). The protein is $\sim 50$ $\mathrm{kDa}$ when transiently overexpressed in CHO cells and based on RT-PCR experiments of human RNA tissue samples, exclusively expressed in testis. The Drosophila melanogaster homologues of NHA1 and NHA2, CG10806 and CG31052, localize to the apical plasma membrane of Malpighian (renal) tubules, together with the proton pumping V-ATPase (Day et al., 2008). Overexpression of CG10806 but not CG31052 in Malpighian tubular cells conferred higher basal but lower stimulated fluid secretion; while overexpression of CG31052 enhanced tubular secretion of $\mathrm{K}^{+}$and $\mathrm{Na}^{+}$. Upon heterologous expression in NHE-deficient yeast $S$. cerevisiae, CG10806 localized to the plasma membrane and conferred protection against excess $\mathrm{K}^{+}$. Heterologously overexpressed CG31052 on the other hand was present on the vacuolar membrane and transformed yeast displayed increased tolerance towards excess $\mathrm{Na}^{+}$. The biologic function of NHA1 remains unclear and $S L C 9 B 1$ has not been linked to human disease

More progress has been made in studies on the closely related NHA2 isoform. Battaglino and coworkers first identified and cloned $S L C 9 B 2$ by a microarray approach conducted to identify genes upregulated in receptor-activation of NF- $\kappa$ B ligand (RANKL)-stimulated osteoclast precursor cells (Battaglino et al., 2007). SiRNA-mediated knock-down significantly inhibited osteoclast differentiation and osteoclast function in vitro. Xiang and co-workers showed that NHA2 was a ubiquitously expressed protein of $\sim 50 \mathrm{kDa}$ in mouse tissues (Fuster et al., 2008; Xiang et al., 2007). Based on immunofluorescence studies of pancreatic $\beta$-cells (INS-1), distal tubular cells of the kidney (MDCK) and NHE-deficient yeast heterologously expressing human NHA2, NHA2 was proposed to be a plasmalemmal NHE. When expressed in NHE-deficient yeast, NHA2 conferred tolerance to $\mathrm{Li}^{+}$and $\mathrm{Na}^{+}$ but not $\mathrm{K}^{+}$, in a pH-dependent manner (Fuster et al., 2008; Xiang et al., 2007). NHA2 was inhibited by phloretin but not by the NHE-inhibitor amilorde, even at high concentrations. Mutation of two conserved aspartic acid residues in the putative transmembrane domain 5 of NHA2 led to loss of salt tolerance in transfected yeast (Xiang et al., 2007). These functional complementation studies in yeast strongly supported that NHA2 was a bona fide NHE. 
However, no direct kinetic evidence exists up to now, that NHAs act as cation $/ \mathrm{H}^{+}$ exchangers. Due to chromosomal localization, inhibitor characteristics, transport properties and its presence on the erythrocyte membrane, NHA2 was proposed to be the long sought $\mathrm{Na}^{+} / \mathrm{Li}^{+}$countertransporter (SLC), that has been linked to the pathogenesis of essential hypertension in humans (Xiang et al., 2007). In support of this hypothesis, Moe and coworkers found NHA2 to be expressed in the distal tubule of rat kidney, a renal tubular segment that is paramount for $\mathrm{Na}^{+}$and blood pressure homeostasis in mammals (Fuster et al., 2008).

Recently, the bone phenotype of a Slc9b2-deficient mouse was published (Hofstetter et al., 2010). Surprisingly, in contrast to published in vitro evidence reviewed above, Slc9b2deficient mice had normal bone density and structural parameters of bone, quantified by high-resolution microcomoputed tomography, were not different in Slc9b2-deficient mice compared to wild-type mice. In addition, in vitro RANKL stimulation of bone marrow cells isolated from wild-type and SIc9b2-deficient mice yielded no differences in osteoclast development and activity. Endogenous NHA2 was present both intracellulary and on the basolateral membrane of RAW 267.4 and bone marrow derived osteoclasts. Intracellulary, NHA2 co-localized with endosomal and lysosomal markers but not with mitochondrial markers. These findings suggested that NHA2 was dispensable for osteoclast differentiation and bone resorption both in vitro and in vivo. At the present time, the reason for the discrepancy between the finding of this study with genetic SIc9b2 deficiency and earlier studies using siRNA-mediated knockdown of $S / c 9 b 2$ remain unclear. Thus, at the present time, the biological role and transport kinetics of NHA2 remain unknown and the subcellular localization of NHA2 remains controversial.

\section{SLC9C/sperm NHEs}

The $S 1 c q_{c} 1$ gene encoding sperm-specific NHE was originally identified by Garbers and coworkers in a mouse spermatid (haploid cell) enriched cDNA library (Wang et al., 2003, 2007). Mammalian SLC9Cs lack distinct orthologs in non-mammalian genomes, and encode an NHE-like N-terminal domain and a long non-conserved C-terminal part with similarity to the Na-transporting carboxylic acid decarboxylase transporter family (NaT-DC), a subfamily of the CPA superfamily (Brett et al., 2005a,b). Sperm NHE was thus grouped apart from NHEs (SLC9A family) and NHAs (SLC9B family) into a new SLC9C subfamily. $S / c 9 c 1$ mRNA expression was restricted to testicular tissue by Northern blotting and dotblot analysis of a wide array of mouse tissues (Wang et al., 2003). The putative open reading frame of mouse $S / c 9 c 1$ encodes 1120 amino acids. Based on hydropathy analysis, the protein is proposed to contain 14 transmembrane domains, which includes a unique voltagesensing motif and a cyclic nucleotide-binding domain (Wang et al., 2003). When transfected in NHE-null fibroblasts, full length sperm NHE expressed poorly. A chimeric construct with the first transmembrane domain of sperm NHE replaced by that of NHE1, however, exhibited improved expression at the plasma membrane and measurable NHE activity, suggesting that sperm NHE is indeed a functional NHE. S/c $9 c 1$-null males are completely infertile with severely diminished sperm motility but normal sperm numbers and sperm morphology (Wang et al., 2003). A sperm NHE-specific polyclonal antibody detected a $\sim 130 \mathrm{kDa}$ protein on Western blot in testicular lysates of wild-type but not $S I c 9 c 1$ knock-out mice. Addition of ammonium chloride and cell-permeant cAMP analogues partially rescued the motility and fertility defects. Knock-out of sperm NHE results in a complete loss of full length bicarbonate-sensitive soluble adenylate cyclase (sAC) with greatly reduced bicarbonate-stimulated soluble adenylyl cyclase activity (Wang et al., 2007). sAC and sperm NHE interact physically with each other, composing a signaling complex at the sperm flagellar plasma membrane that seems to be vital for control of intracellular bicarbonate and 
cAMP levels, both of which are of great importance for sperm capacitation and motility. Although a likely candidate, sperm NHE has not been linked to male infertility in humans.

SLC9C2 (also known as NHE11) is another member of the SLC9C family for which no functional data exist. Based on EST databases it is expressed in testis and probably also present in ovary, skin and connective tissue.

\section{Summary}

Future progress in understanding of the SLC9 gene family, which currently is undergoing increased understanding of structure and function relationships and increased insights in regulation normally and in models of disease, is likely to include insights into the pathophysiology of multiple diseases. We predict that therapies for these diseases as well as other medical conditions will be approachable by altering SLC9 gene family function including by use of drugs and peptides that mimic normal regulation of these proteins.

\section{Acknowledgments}

We apologize to the many investigators whose work could not be quoted and/or referenced due to space contraints. National Institutes of Health, NIDDK Grants RO1-DK26523, RO1-DK061765, PO1-DK072084, and R24DK64388 (The Hopkins Basic Research Digestive Diseases Development Core Center), and the Hopkins Center for Epithelial Disorders; Swiss National Science Foundation grant (\# 3100A0-117732), the Swiss National Centre of Competence in Research (NCCR TransCure), the Novartis Research Foundation, and by a Medical Research Position Award of the Foundation Prof. Dr. Max Cloëtta.

\section{References}

Aharonovitz O, Zaun HC, Balla T, York JD, Orlowski J, Grinstein S. Intracellular pH regulation by Na ${ }^{+} / \mathrm{H}^{+}$exchange requires phosphatidylinositol 4,5-bisphosphate. J. Cell Biol. 2000; 150:213-224. [PubMed: 10893269]

Alexander RT, Jaumouillé V, Yeung T, Furuya W, Peltekova I, Boucher A, Zasloff M, Orlowski J, Grinstein S. Membrane surface charge dictates the structure and function of the epithelial $\mathrm{Na}^{+} / \mathrm{H}^{+}$ exchanger. EMBO J. 2011; 30:679-691. [PubMed: 21245831]

Alexander RT, Malevanets A, Durkan AM, Kocinsky HS, Aronson PS, Orlowski J, Grinstein S. Membrane curvature alters the activation kinetics of the epithelial $\mathrm{Na}^{+} / \mathrm{H}^{+}$exchanger, NHE3. J. Biol. Chem. 2007; 282:7376-7384. [PubMed: 17218318]

Ammar YB, Takeda S, Hisamitsu T, Mori H, Wakabayashi S. Crystal structure of CHP2 complexed with NHE1-cytosolic region and an implication for pH regulation. EMBO J. 2006; 25:2315-2325. [PubMed: 16710297]

Attaphitaya S, Nehrke K, Melvin JE. Acute inhibition of brain-specific $\mathrm{Na}^{+} / \mathrm{H}^{+}$exchanger isoform 5 by protein kinases A and C and cell shrinkage. Am. J. Physiol. Cell. Physiol. 2001; 281:C1146C1157. [PubMed: 11546650]

Battaglino RA, Pham L, Morse LR, Vokes M, Sharma A, Odgren PR, Yang M, Sasaki H, Stashenko P. NHA-oc/NHA2: A mitochondrial cation-proton antiporter selectively expressed in osteoclasts. Bone. 2007; 42:180-192. [PubMed: 17988971]

Baum M, Martin MG, Booth IW, Holmberg C, Twombley K, Zhang Q, Gattineni J, Moe O. Nucleotide sequence of the $\mathrm{Na}^{+} / \mathrm{H}^{+}$exchanger-8 (NHE8) in patients with congenital sodium diarrhea. J. Pediatr. Gastroenterol. Nutr. 2011; 53:474-477. [PubMed: 21666503]

Baumgartner M, Patel H, Barber DL. Na ${ }^{+} / \mathrm{H}^{+}$exchanger NHE1 as plasma membrane scaffold in the assembly of signaling complexes. Am. J. Physiol. Cell. Physiol. 2004; 287:C844-C850. [PubMed: 15355855]

Becker AM, Zhang J, Goyal S, Dwarakanath V, Aronson PS, Moe OW, Baum M. Ontogeny of NHE8 in the rat proximal tubule. Am. J. Physiol. Renal Physiol. 2007; 293:F255-F261. [PubMed: 17429030] 
Bell SM, Schreiner CM, Schultheis PJ, Miller ML, Evans RL, Vorhees CV, Shull GE, Scott WJ. Targeted disruption of the murine Nhe1 locus induces ataxia, growth retardation, and seizures. Am. J. Physiol. 1999; 276:C788-C795. [PubMed: 10199808]

Ben, Ammar Y.; Takeda, S.; Sugawara, M.; Miyano, M.; Mori, H.; Wakabayashi, S. Crystallization and preliminary crystallographic analysis of the human calcineurin homologous protein CHP2 bound to the cytoplasmic region of the $\mathrm{Na}^{+} / \mathrm{H}^{+}$exchanger NHE1. Acta Crystallogr. Sect. F. Struct. Biol. Cryst. Commun. 2005; 61:956-958.

Bobulescu IA, Moe OW. $\mathrm{Na}^{+} / \mathrm{H}^{+}$exchangers in renal regulation of acid-base balance. Semin Nephrol. 2006; 26:334-344. [PubMed: 17071327]

Bourgeois S, Meer LV, Wootla B, Bloch-Faure M, Chambrey R, Shull GE, Gawenis LR, Houillier P. NHE4 is critical for the renal handling of ammonia in rodents. J. Clin. Invest. 2010; 120:18951904. [PubMed: 20484819]

Brant SR, Yun CH, Donowitz M, Tse CM. Cloning, tissue distribution, and functional analysis of the human $\mathrm{Na}^{+} / \mathrm{N}^{+}$exchanger isoform, NHE3. Am. J. Physiol. 1995; 269:C198-C206. [PubMed: 7631746]

Brett CL, Donowitz M, Rao R. Evolutionary origins of eukaryotic sodium/proton exchangers. Am. J. Physiol. Cell. Physiol. 2005a; 288:C223-C239. [PubMed: 15643048]

Brett CL, Tukaye DN, Mukherjee S, Rao R. The yeast endosomal $\mathrm{Na}^{+} \mathrm{K}^{+} / \mathrm{H}^{+}$exchanger Nhx1 regulates cellular $\mathrm{pH}$ to control vesicle trafficking. Mol. Biol. Cell. 2005b; 16:1396-1405. [PubMed: 15635088]

Brett CL, Wei Y, Donowitz M, Rao R. Human $\mathrm{Na}^{+} / \mathrm{H}^{+}$exchanger isoform 6 is found in recycling endosomes of cells, not in mitochondria. Am. J. Physiol. Cell. Physiol. 2002; 282:C1031-C1041. [PubMed: 11940519]

Cha B, Tse M, Yun C, Kovbasnjuk O, Mohan S, Hubbard A, Arpin M, Donowitz M. The NHE3 juxtamembrane cytoplasmic domain directly binds ezrin: dual role in NHE3 trafficking and mobility in the brush border. Mol Biol Cell. 2006; 17:2661-2673. [PubMed: 16540524]

Chambrey R, Achard JM, Warnock DG. Heterologous expression of rat NHE4: a highly amilorideresistant $\mathrm{Na}^{+} / \mathrm{H}^{+}$exchanger isoform. Am. J. Physiol. 1997; 272:C90-C98. [PubMed: 9038815]

Choi JY, Shah M, Lee MG, Schultheis PJ, Shull GE, Muallem S, Baum M. Novel amiloride-sensitive sodium-dependent proton secretion in the mouse proximal convoluted tubule. J. Clin. Invest. 2000; 105:1141-1146. [PubMed: 10772659]

Chow CW, Khurana S, Woodside M, Grinstein S, Orlowski J. The epithelial $\mathrm{Na}^{+} / \mathrm{H}^{+}$exchanger, NHE3, is internalized through a clathrin-mediated pathway. J. Biol. Chem. 1999; 274:3755137558. [PubMed: 10608808]

Cox GA, Lutz CM, Yang CL, Biemesderfer D, Bronson RT, Fu A, Aronson PS, Noebels JL, Frankel WN. Sodium/hydrogen exchanger gene defect in slow-wave epilepsy mutant mice. Cell. 1997; 91:139-148. [PubMed: 9335342]

Day JP, Wan S, Allan AK, Kean L, Davies SA, Gray JV, Dow JA. Identification of two partners from the bacterial Kef exchanger family for the apical plasma membrane V-ATPase of Metazoa. J. Cell Sci. 2008; 121:2612-2619. [PubMed: 18628302]

Denker SP, Huang DC, Orlowski J, Furthmayr H, Barber DL. Direct binding of the Na-H exchanger NHE1 to ERM proteins regulates the cortical cytoskeleton and cell shape independently of $\mathrm{H}^{+}$ translocation. Mol. Cell. 2000; 6:1425-1436. [PubMed: 11163215]

Diering GH, Church J, Numata M. Secretory carrier membrane protein 2 regulates cell-surface targeting of brain-enriched $\mathrm{Na}^{+} / \mathrm{H}^{+}$exchanger NHE5. J. Biol. Chem. 2009; 284:13892-13903. [PubMed: 19276089]

Diering GH, Mills F, Bamji SX, Numata M. Regulation of dendritic spine growth through activitydependent recruitment of the brain-enriched Na/H exchanger NHE5. Mol. Biol. Cell. 2011; 22:2246-2257. [PubMed: 21551074]

Donowitz M, Li X. Regulatory binding partners and complexes of NHE3. Physiol. Rev. 2007; 87:825872. [PubMed: 17615390]

Donowitz M, Mohan S, Zhu CX, Chen TE, Lin R, Cha B, Zachos NC, Murtazina R, Sarker R, Li X. NHE3 regulatory complexes. J. Exp. Biol. 2009; 212:1638-1646. [PubMed: 19448074] 
Eladari D, Chambrey R. Ammonium transport in the kidney. J. Nephrol. 2010; 23(Suppl 16):S28-S34. [PubMed: 21170885]

Fiori M, Gras EG, Amorena C. Decreased NHE8 isoform expression and defective acidification in proximal convoluted tubules of senile rats. Age (Dordr.). 2009; 31:77-84. [PubMed: 19234771]

Fuster DG, Zhang J, Shi M, Bobulescu IA, Andersson S, Moe OW. Characterization of the sodium/ hydrogen exchanger NHA2. J. Am. Soc. Nephrol. 2008; 19:1547-1556. [PubMed: 18508966]

Gattineni J, Sas D, Dagan A, Dwarakanath V, Baum M. Effect of thyroid hormone on the postnatal renal expression of NHE8. Am. J. Physiol. Renal Physiol. 2008; 294:F198-F204. [PubMed: 17977906]

Gawenis LR, Greeb JM, Prasad V, Grisham C, Sanford LP, Doetschman T, Andringa A, Miller ML, Shull GE. Impaired gastric acid secretion in mice with a targeted disruption of the NHE4 Na $/ \mathrm{H}^{+}$ exchanger. J. Biol. Chem. 2005; 280:12781-12789. [PubMed: 15684419]

Gawenis LR, Ledoussal C, Judd LM, Prasad V, Alper SL, Stuart-Tilley A, Woo AL, Grisham C, Sanford LP, Doetschman T, Miller ML, Shull GE. Mice with a targeted disruption of the AE2 Cl-/ HCO3- exchanger are achlorhydric. J. Biol. Chem. 2004; 279:30531-30539. [PubMed: 15123620]

Gilfillan GD, Selmer KK, Roxrud I, Smith R, Kyllerman M, Eiklid K, Kroken M, Mattingsdal M, Egeland T, Stenmark H, Sjøholm H, Server A, Samuelsson L, Christianson A, Tarpey P, Whibley A, Stratton MR, Futreal PA, Teague J, Edkins S, Gecz J, Turner G, Raymond FL, Schwartz C, Stevenson RE, Undlien DE, Strømme P. SLC9A6 mutations cause X-linked mental retardation, microcephaly, epilepsy, and ataxia, a phenotype mimicking Angelman syndrome. Am. J. Hum. Genet. 2008; 82:1003-1010. [PubMed: 18342287]

Girardi AC, Degray BC, Nagy T, Biemesderfer D, Aronson PS. Association of $\mathrm{Na}^{+} / \mathrm{H}^{+}$exchanger isoform NHE3 and dipeptidyl peptidase IV in the renal proximal tubule. J. Biol. Chem. 2001; 276:46671-46677. [PubMed: 11590171]

Goyal S, Mentone S, Aronson PS. Immunolocalization of NHE8 in rat kidney. Am. J. Physiol. Renal Physiol. 2005; 288:F530-F538. [PubMed: 15522984]

Gu XQ, Yao H, Haddad GG. Increased neuronal excitability and seizures in the $\mathrm{Na}^{+} / \mathrm{H}^{+}$exchanger null mutant mouse. Am. J. Physiol. Cell. Physiol. 2001; 281:C496-C503. [PubMed: 11443048]

Hayashi H, Szászi K, Coady-Osberg N, Furuya W, Bretscher AP, Orlowski J, Grinstein S. Inhibition and redistribution of NHE3, the apical $\mathrm{Na}^{+} / \mathrm{H}^{+}$exchanger, by Clostridium difficile toxin. J. Gen. Physiol. 2004; 123:491-504. [PubMed: 15078917]

Hayashi H, Aharonovitz O, Alexander RT, Touret N, Furuya W, Orlowski J, Grinstein S. $\mathrm{Na}^{+} / \mathrm{H}^{+}$ exchange and $\mathrm{pH}$ regulation in the control of neutrophil chemokinesis and chemotaxis. Am. J. Physiol. Cell. Physiol. 2008; 294:C526-C534. [PubMed: 18094149]

He P, Zhang H, Yun CC. RBIT, inositol 1,4,5-triphosphate (IP3) receptor-binding protein released with IP3, binds $\mathrm{Na}^{+} / \mathrm{H}^{+}$exchanger NHE3 and activates NHE3 activity in response to calcium. J. Biol. Chem. 2008; 283:33544-33545. [PubMed: 18829453]

Hecht G, Hodges K, Gill RK, Kear F, Tyagi S, Malakooti J, Ramaswamy K, Dudeja PK. Differential regulation of $\mathrm{Na}^{+} / \mathrm{H}^{+}$exchange isoform activities by enteropathogenic $E$ coli in human intestinal epithelial cells. Am. J. Physiol. Gastrointest Liver Physiol. 2004; 287:G370-G378. [PubMed: 15075254]

Hill JK, Brett CL, Chyou A, Kallay LM, Sakaguchi M, Rao R, Gillespie PG. Vestibular hair bundles control $\mathrm{pH}$ with $\left(\mathrm{Na}^{+}, \mathrm{K}^{+}\right) / \mathrm{H}^{+}$exchangers NHE6 and NHE9. J. Neurosci. 2006; 26:9944-9955. [PubMed: 17005858]

Hofstetter W, Siegrist M, Simonin A, Bonny O, Fuster DG. Sodium/hydrogen exchanger NHA2 in osteoclasts: subcellular localization and role in vitro and in vivo. Bone. 2010; 47:331-340. [PubMed: 20441802]

Hoogerwerf WA, Tsao SC, Devuyst O, Levine SA, Yun CH, Yip JW, Cohen ME, Wilson PD, Lazenby AJ, Tse CM, Donowitz M. NHE2 and NHE3 are human and rabbit intestinal brushborder proteins. Am. J. Physiol. 1996; 270:G29-G41. [PubMed: 8772498]

Hunte C, Screpanti E, Venturi M, Rimon A, Padan E, Michel H. Structure of a Na ${ }^{+} / \mathrm{H}^{+}$antiporter and insights into mechanism of action and regulation by $\mathrm{pH}$. Nature. 2005; 435:1197-1202. [PubMed: 15988517] 
Ikeda T, Schmitt B, Pouysségur J, Wakabayashi S, Shigekawa M. Identification of cytoplasmic subdomains that control $\mathrm{pH}$-sensing of the $\mathrm{Na}^{+} / \mathrm{H}^{+}$exchanger (NHE1): $\mathrm{pH}$-maintenance, ATPsensitive, and flexible loop domains. J. Biochem. 1997; 121:230-295.

Jacob P, Rossmann H, Lamprecht G, Kretz A, Neff C, Lin-Wu E, Gregor M, Groneberg DA, Kere J, Seidler U. Down-regulated in adenoma mediates apical $\mathrm{Cl}-/ \mathrm{HCO} 3-$ exchange in rabbit rat human duodenum. Gastroenterology. 2002; 122:709-724. [PubMed: 11875004]

Janecki AJ, Montrose MH, Zimniak P, Zweibaum A, Tse CM, Khurana S, Donowitz M. Subcellular redistribution is involved in acute regulation of the brush border $\mathrm{Na}^{+} / \mathrm{H}^{+}$exchanger isoform 3 in human colon adenocarcinoma cell line Caco-2. Protein kinase C-mediated inhibition of the exchanger. J. Biol. Chem. 1998; 273:8790-8798. [PubMed: 9535857]

Kagami T, Chen S, Memar P, Choi M, Foster LJ. Numata Identification and biochemical characterization of the SLC9A7 interactome. Mol. Membr. Biol. 2008; 25:436-447. [PubMed: 18654930]

Kallay LM, Brett CL, Tukaye DN, Wemmer MA, Chyou A, Odorizzi G, Rao R. The endosomal Na ${ }^{+}$ $\left(\mathrm{K}^{+}\right) / \mathrm{H}^{+}$exchanger NHX1/VPS44 functions independently and downstream of multivesicular body formation. J. Biol. Chem. 2011; 286:44067-44077. [PubMed: 21998311]

Kang'ethe W, Aimanova KG, Pullikuth AK, Gill SS. NHE8 mediates amiloride-sensitive $\mathrm{Na}^{+} / \mathrm{H}^{+}$ exchange across mosquito Malpighian tubules and catalyzes $\mathrm{Na}^{+}$and $\mathrm{K}^{+}$transport in reconstituted proteoliposomes. Am. J. Physiol. Renal Physiol. 2007; 292:F1501-F1512. [PubMed: 17287198]

Karmazyn M. Amiloride enhances postischemic ventricular recovery: possible role of $\mathrm{Na}^{+} / \mathrm{H}^{+}$ exchange. Am. J. Physiol. 1988; 255:H608-H615. [PubMed: 2843057]

Kiela PR, Lau bitz D, Larmonier CB, Midura-Kiela MT, Lipko MA, Janikashvili N, Bai A, Thurston $\mathrm{R}$, Ghishan FK. Changes in mucosal homeostasis predispose NHE3 knockout mice to increased susceptibility to DSS-induced epithelial injury. Gastroenterology. 2009; 137:965-975. [PubMed: 19450596]

Koester S, Pavkov-Keller T, Kuehlbrandt W, Yildiz O. Structure of human $\mathrm{Na}^{+} / \mathrm{H}^{+}$exchanger NHE1 regulatory region in complex with $\mathrm{CaM}$ and $\mathrm{Ca}^{+}{ }^{\mathrm{J}}$. Biol. Chem. 2011; 286:40954-40961. [PubMed: 21931166]

Lagarde AE, Franchi AJ, Paris S, Pouyssegur JM. Effect of mutations affecting $\mathrm{Na}^{+}: \mathrm{H}^{+}$antiport activity on tumorigenic potential of hamster lung fibroblasts. J. Cell. Biochem. 1988; 36:249-260. [PubMed: 2837494]

Landau M, Herz K, Padan E, Ben-Tal N. Model structure of the $\mathrm{Na}^{+} / \mathrm{H}^{+}$exchanger 1 (NHE1): functional and clinical implications. J. Biol. Chem. 2007; 282:37854-37863. [PubMed: 17981808]

Lawrence SP, Bright NA, Luzio JP, Bowers K. The sodium/proton exchanger NHE8 regulates late endosomal morphology and function. Mol. Biol. Cell. 2010; 21:3540-3551. [PubMed: 20719963]

Lazdunski M, Frelin C, Vigne P. The sodium/hydrogen exchange system in cardiac cells: its biochemical and pharmacological properties and its role in regulating internal concentrations of sodium and internal pH. J. Mol. Cell. Cardiol. 1985; 17:1029-1042. [PubMed: 3001319]

Lee JS, Lee YM, Kim JY, Park HW, Grinstein S, Orlowski J, Kim E, Kim KH, Lee MG. BetaPix upregulates $\mathrm{Na}^{+} / \mathrm{H}^{+}$exchanger 3 through a Shank2-mediated protein-protein interaction. J. Biol. Chem. 2010; 285:8104-8113. [PubMed: 20080968]

Li X, Galli T, Leu S, Wade JB, Weinman EJ, Leung G, Cheong A, Louvard D, Donowitz M. Na ${ }^{+}-\mathrm{H}^{+}$ exchanger 3 (NHE3) is present in lipid rafts in the rabbit ileal brush border: a role for rafts in trafficking and rapid stimulation of NHE3. J. Physiol. 2001; 537:537-552. [PubMed: 11731584]

Lin PJ, Williams WP, Luu Y, Molday RS, Orlowski J, Numata M. Secretory carrier membrane proteins interact and regulate trafficking of the organellar $\left(\mathrm{Na}^{+}, \mathrm{K}^{+}\right) / \mathrm{H}^{+}$exchanger NHE7. Cell Sci. 2005; 118:1885-1897.

Lin R, Murtazina R, Cha B, Chakraborty M, Sarker R, Chen TE, Lin Z, Hogema BM, de Jonge HR, Seidler U, Turner JR, Li X, Kovbasnjuk O, Donowitz M. d-glucose acts via sodium/glucose cotransporter 1 to increase NHE3 in mouse jejunal brush border by a Na ${ }^{+} / \mathrm{H}^{+}$exchange regulatory factor 2-dependent process. Gastroenterology. 2011; 140:560-571. [PubMed: 20977906]

Lukashova V, Szabo EZ, Jinadasa T, Mokhov A, Litchfield DW, Orlowski J. CK2 phosphorylation of an acidic Ser/Thr di-isoleucine motif in the $\mathrm{Na}^{+} / \mathrm{H}^{+}$exchanger NHE5 isoform promotes 
association with beta-arrestin2 and endocytosis. J. Biol. Chem. 2011; 286:11456-11468. [PubMed: 21296876]

Mishima M, Wakabayashi S, Kojima C. Solution structure of the cytoplasmic region of $\mathrm{Na}^{+} / \mathrm{H}^{+}$ exchanger 1 complexed with essential cofactor calcineurin B homologous protein 1. J. Biol. Chem. 2007; 282:2741-2751. [PubMed: 17050540]

Morrow EM, Yoo SY, Flavell SW, Kim TK, Lin Y, Hill RS, Mukaddes NM, Balkhy S, Gascon G, Hashmi A, Al-Saad S, Ware J, Joseph RM, Greenblatt R, Gleason D, Ertelt JA, Apse KA, Bodell A, Partlow JN, Barry B, Yao H, Markianos K, Ferland RJ, Greenberg ME, Walsh CA. Identifying autism loci and genes by tracing recent shared ancestry. Science. 2008; 321:218-223. [PubMed: 18621663]

Nakamura N, Tanaka S, Teko Y, Mitsui K, Kanazawa H. Four Na ${ }^{+} / \mathrm{H}^{+}$exchanger isoforms are distributed to Golgi and post-Golgi compartments and are involved in organelle $\mathrm{pH}$ regulation. J. Biol. Chem. 2005; 280:1561-1572. [PubMed: 15522866]

Nakamura TY, Iwata Y, Arai Y, Komamura K, Wakabayashi S. Activation of $\mathrm{Na}^{+} / \mathrm{H}^{+}$exchanger 1 is sufficient to generate $\mathrm{Ca}^{+}$signals that induce cardiac hypertrophy and heart failure. Circ. Res. 2008; 103:891-899. [PubMed: 18776042]

Nass R, Cunningham KW, Rao R. Intracellular sequestration of sodium by a novel $\mathrm{Na}^{+} / \mathrm{H}^{+}$exchanger in yeast is enhanced by mutations in the plasma membrane $\mathrm{H}^{+}$-ATPase. Insights into mechanisms of sodium tolerance. J. Biol. Chem. 1997; 272:26145-26152. [PubMed: 9334180]

Nien-Jen H, Iwata S, Cameron AD, Drew D. Crystal structure of a bacterial homologue of the bile acid sodium symporter ASBT. Nature. 2011; 478:408-411. [PubMed: 21976025]

Numata M, Orlowski J. Molecular cloning and characterization of a novel $\left(\mathrm{Na}^{+}, \mathrm{K}^{+}\right) / \mathrm{H}^{+}$exchanger localized to the trans-Golgi network. J. Biol. Chem. 2001; 276:17387-17394. [PubMed: 11279194]

Ohgaki R, Fukura N, Matsushita M, Mitsui K, Kanazawa H. Cell surface levels of organellar $\mathrm{Na}^{+} / \mathrm{H}^{+}$ exchanger isoform 6 are regulated by interaction with RACK1. J. Biol. Chem. 2008; 283:44174429. [PubMed: 18057008]

Ohgaki R, van IJzendoorn SC, Matsushita M, Hoekstra D, Kanazawa H. Organellar $\mathrm{Na}^{+} / \mathrm{H}^{+}$ exchangers: novel players in organelle $\mathrm{pH}$ regulation and their emerging functions. Biochemistry. 2011; 50:443-450. [PubMed: 21171650]

Onishi I, Lin PJ, Diering GH, Williams WP, Numata M. RACK1 associates with NHE5 in focal adhesions and positively regulates the transporter activity. Cell Signal. 2007; 19:194-203. [PubMed: 16920332]

Orlowski J, Grinstein S. Diversity of the mammalian sodium/proton exchanger SLC9 gene family. Pflugers Arch. 2004; 447:549-565. [PubMed: 12845533]

Padan E, Kozachkov L, Herz K, Rimon A. NhaA crystal structure: functional-structural insights. J. Exp. Biol. 2009; 212:1593-1603. [PubMed: 19448069]

Papadopoulos JS, Agarwala R. COBALT: constraint-based alignment tool for multiple protein sequences. Bioinformatics. 2007; 23:1073-1079. [PubMed: 17332019]

Poetsch M, Nottebaum BJ, Wingenfeld L, Frede S, Vennemann M, Bajanowski T. Impact of sodium/ proton exchanger 3 gene variants on sudden infant death syndrome. J. Pediatr. 2010; 156:44-48. [PubMed: 19772970]

Reshkin SJ, Bellizzi A, Albarani V, Guerra L, Tommasino M, Paradiso A, Casavola V. Phosphoinositide 3-kinase is involved in the tumor-specific activation of human breast cancer cell $\mathrm{Na}^{+} / \mathrm{H}^{+}$exchange, motility, and invasion induced by serum deprivation. J. Biol. Chem. 275:53615369. [PubMed: 10681510]

Reshkin SJ, Bellizzi A, Caldeira S, Albarani V, Malanchi I, Poignee M, Alunni-Fabbroni M, Casavola $\mathrm{V}$, Tommasino M. $\mathrm{Na}^{+} / \mathrm{H}^{+}$exchanger-dependent intracellular alkalinization is an early event in malignant transformation and plays an essential role in the development of subsequent transformation-associated phenotypes. FASEB J. 2000b; 14:2185-2197. [PubMed: 11053239]

Roxrud I, Raiborg C, Gilfillan GD, Strømme P, Stenmark H. Dual degradation mechanisms ensure disposal of NHE6 mutant protein associated with neurological disease. Exp. Cell Res. 2009; 315:3014-3027. [PubMed: 19619532] 
Sardet C, Counillon L, Franchi A, Pouyssegur J. Growth factors induce phosphorylation of the $\mathrm{Na}^{+} / \mathrm{H}^{+}$ antiporter, glycoprotein of $110 \mathrm{kD}$. Science. 1990; 247:723-726. [PubMed: 2154036]

Schultheis PJ, Clarke LL, Meneton P, Harline M, Boivin GP, Stemmermann G, Duffy JJ, Doetschman T, Miller ML, Shull GE. Targeted disruption of the murine $\mathrm{Na}^{+} / \mathrm{H}^{+}$exchanger isoform 2 gene causes reduced viability of gastric parietal cells and loss of net acid secretion. J. Clin. Invest. 1998a; 101:1243-1253. [PubMed: 9502765]

Schultheis PJ, Clarke LL, Meneton P, Miller ML, Soleimani M, Gawenis LR, Riddle TM, Duffy JJ, Doetschman T, Wang T, Giebisch G, Aronson PS, Lorenz JN, Shull GE. Renal and intestinal absorptive defects in mice lacking the NHE3 $\mathrm{Na}^{+} / \mathrm{H}^{+}$exchanger. Nat. Genet. 1998b; 19:282-285. [PubMed: 9662405]

Schushan M, Xiang M, Bogomiakov P, Padan E, Rao R, Ben-Tal N. Model-guided mutagenesis drives functional studies of human NHA2, implicated in hypertension. J. Mol. Biol. 2010; 396:11811196. [PubMed: 20053353]

Simonin A, Fuster D. Nedd4-1 and beta-arrestin-1 are key regulators of $\mathrm{Na}^{+} / \mathrm{H}^{+}$exchanger 1 ubiquitylation, endocytosis, and function. J. Biol. Chem. 2010; 285:38293-38303. [PubMed: 20855896]

Sotak M, Polidarova L, Musilkova J, Hock M, Sumová A, Pacha J. Circadian regulation of electrolyte absorption in the rat colon. Am. J. Physiol. Gastrointest Liver Physiol. 2011 Epub ahead of print.

Subramanya SB, Rajendran VM, Srinivasan P, Nanda Kumar NS, Ramakrishna BS, Binder HJ. Differential regulation of cholera toxin-inhibited $\mathrm{Na}-\mathrm{H}$ exchange isoforms by butyrate in rat ileum. Am. J. Physiol. Gastrointest. Liver Physiol. 2007; 293:G857-G863. [PubMed: 17690171]

Sullivan S, Alex P, Dassopoulos T, Zachos NC, Iacobuzio-Donahue C, Donowitz M, Brant SR, Cuffari C, Harris ML, Datta LW, Conklin L, Chen Y, Li X. Downregulation of sodium transporters and NHERF proteins in IBD patients and mouse colitis models: potential contributors to IBD-associated diarrhea. Inflamm. Bowel Dis. 2009; 15:261-274. [PubMed: 18942765]

Szabo EZ, Numata M, Lukashova V, Iannuzzi P, Orlowski J. Beta-Arrestins bind and decrease cellsurface abundance of the $\mathrm{Na}^{+} / \mathrm{H}^{+}$exchanger NHE5 isoform. Proc. Natl. Acad. Sci. USA. 2005; 102:2790-2795. [PubMed: 15699339]

Takahashi Y, Hosoki K, Matsushita M, Funatsuka M, Saito K, Kanazawa H, Goto Y, Saitoh S. A lossof-function mutation in the SLC9A6 gene causes X-linked mental retardation resembling Angelman syndrome. Am. J. Med. Genet. B Neuropsychiatr. Genet. 2011; 156B:799-807. [PubMed: 21812100]

Tse CM, Levine SE, Yun CH, Montrose MH, Little PJ, Pouyssegur J, Donowitz M. Cloning and expression of a rabbit cDNA encoding a serum-activated ethylisopropylamiloride-resistant epithelial $\mathrm{Na}^{+} / \mathrm{H}^{+}$exchanger isoform (NHE2). J. Biol. Chem. 1993; 268:11917-11924. [PubMed: 7685025]

Turner JR, Black ED. NHE3-dependent cytoplasmic alkalinization is triggered by $\mathrm{Na}^{+}$-glucose cotransport in intestinal epithelia. Am. J. Physiol. Cell Physiol. 2001; 281:C1533-C1541. [PubMed: 11600416]

Wakabayashi S, Pang T, Su X, Shigekawa M. A novel topology model of the human $\mathrm{Na}^{+} / \mathrm{H}^{+}$ exchanger isoform 1. J. Biol. Chem. 2000; 275:7942-7949. [PubMed: 10713111]

Wang C, Xu H, Chen H, Li J, Zhang B, Tang C, Ghishan FK. Somatostatin stimulates intestinal NHE8 expression via p38 MAPK pathway. Am. J. Physiol. Cell. Physiol. 2011; 300:C375-C382. [PubMed: 21106692]

Wang Z, Orlowski J, Shull GE. Primary structure and functional expression of a novel gastrointestinal isoform of the rat Na/H exchanger. J. Biol. Chem. 1993; 268:11925-11928. [PubMed: 7685026]

Wang D, Hu J, Bobulescu IA, Quill TA, McLeroy P, Moe OW, Garbers DL. A sperm-specific Na ${ }^{+} / \mathrm{H}^{+}$ exchanger (sNHE) is critical for expression and in vivo bicarbonate regulation of the soluble adenylyl cyclase (sAC). Proc. Natl. Acad. Sci. USA. 2007; 104:9325-9330. [PubMed: 17517652]

Wang D, King SM, Quill TA, Doolittle LK, Garbers DL. A new sperm-specific $\mathrm{Na}^{+} / \mathrm{H}^{+}$exchanger required for sperm motility and fertility. Nat. Cell Biol. 2003; 5:1117-1122. [PubMed: 14634667]

Wiemann M, Schwark JR, Bonnet U, Jansen HW, Grinstein S, Baker RE, Lang HJ, Wirth K, Bingmann D. Selective inhibition of the $\mathrm{Na}^{+} / \mathrm{H}^{+}$exchanger type 3 activates $\mathrm{CO} 2 / \mathrm{H}^{+}$-sensitive medullary neurons. Pflugers Arch. 1999; 438:255-262. [PubMed: 10398853] 
Woo AL, Gildea LA, Tack LM, Miller ML, Spicer Z, Millhorn DE, Finkelman FD, Hassett DJ, Shull GE. In vivo evidence for interferon-gamma-mediated homeostatic mechanisms in small intestine of the NHE3 $\mathrm{Na}^{+} / \mathrm{H}^{+}$exchanger knockout model of congenital diarrhea. J. Biol. Chem. 2002; 277:49036-49046. [PubMed: 12370192]

Xia Y, Zhao P, Xue J, Gu XQ, Sun X, Yao H, Haddad GG. $\mathrm{Na}^{+}$channel expression and neuronal function in the $\mathrm{Na}^{+} / \mathrm{H}^{+}$exchanger 1 null mutant mouse. J. Neurophysiol. 2003; 89:229-236. [PubMed: 12522174]

Xiang M, Feng M, Muend S, Rao R. A human $\mathrm{Na}^{+} / \mathrm{H}^{+}$antiporter sharing evolutionary origins with bacterial NhaA may be a candidate gene for essential hypertension. Proc. Natl. Acad. Sci. USA. 2007; 104:18677-18681. [PubMed: 18000046]

Xinhan L, Matsushita M, Numaza M, Taguchi A, Mitsui K, Kanazawa H. Na ${ }^{+} / \mathrm{H}^{+}$exchanger isoform 6 (NHE6 / SLC9A6) is involved in clathrin-dependent endocytosis of transferrin. Am. J. Physiol. Cell. Physiol. 2011 Epub ahead of print.

Xu H, Chen H, Dong J, Lynch R, Ghishan FK. Gastrointestinal distribution and kinetic characterization of the sodium-hydrogen exchanger isoform 8 (NHE8). Cell. Physiol. Biochem. 2008; 21:109-116. [PubMed: 18209477]

Xu H, Li J, Chen R, Zhang B, Wang C, King N, Chen H, Ghishan FK. NHE2×3 DKO mice exhibit gender-specific NHE8 compensation. Am. J. Physiol. Gastrointest. Liver Physiol. 2011; 300:G647-G653. [PubMed: 21252044]

Xu H, Zhang B, Li J, Chen H, Wang C, Ghishan FK. Transcriptional inhibition of intestinal NHE8 expression by glucocorticoids involves Pax5. Am. J. Physiol. Gastrointest. Liver Physiol. 2010; 299:G921-G927. [PubMed: 20671194]

Xue L, Aihara E, Wang TC, Montrose MH. Trefoil factor 2 requires Na/H exchanger 2 activity to enhance mouse gastric epithelial repair. J. Biol. Chem. 2011; 286:38375-38382. [PubMed: 21900251]

Yasuda Y, Hashimoto R, Yamamori H, Ohi K, Fukumoto M, Umeda-Yano S, Mohri I, Ito A, Taniike M, Takeda M. Gene expression analysis in lymphoblasts derived from patients with autism spectrum disorder. Mol. Autism. 2011; 26:9. [PubMed: 21615902]

Ye G, Chen C, Han D, Xiong X, Kong Y, Wan B, Yu L. Cloning of a novel human NHEDC1 $\left(\mathrm{Na}^{+} / \mathrm{H}^{+}\right.$ exchanger like domain containing 1) gene expressed specifically in testis. Mol. Biol. Rep. 2006; 33:175-180. [PubMed: 16850186]

Yeruva S, Farkas K, Hubricht J, Rode K, Riederer B, Bachmann O, Cinar A, Rakonczay Z, Molnár T, Nagy F, Wedemeyer J, Manns M, Raddatz D, Musch MW, Chang EB, Hegyi P, Seidler U. Preserved $\mathrm{Na}^{+} / \mathrm{H}^{+}$exchanger isoform 3 expression and localization, but decreased NHE3 function indicate regulatory sodium transport defect in ulcerative colitis. Inflamm. Bowel Dis. 2010; 16:1149-1161. [PubMed: 20027604]

Zachos NC, Kovbasnjuk O, Donowitz M. Regulation of intestinal electroneutral sodium absorption and the brush border $\mathrm{Na}^{+} / \mathrm{H}^{+}$exchanger by intracellular calcium. Ann. NY Acad. Sci. 2009; 1165:240-248. [PubMed: 19538312]

Zachos NC, Tse M, Donowitz M. Molecular physiology of intestinal $\mathrm{Na}^{+} / \mathrm{H}^{+}$exchange. Annu. Rev. Physiol. 2005; 67:411-443. [PubMed: 15709964]

Zhu X, Cha B, Zachos NC, Sarker R, Chakraborty M, Chen TE, Kovbasnjuk O, Donowitz M. Elevated calcium acutely regulates dynamic interactions of NHERF2 and NHE3 proteins in opossum kidney (OK) cell microvilli. J. Biol. Chem. 2011; 286:34486-34496. [PubMed: 21799002] 


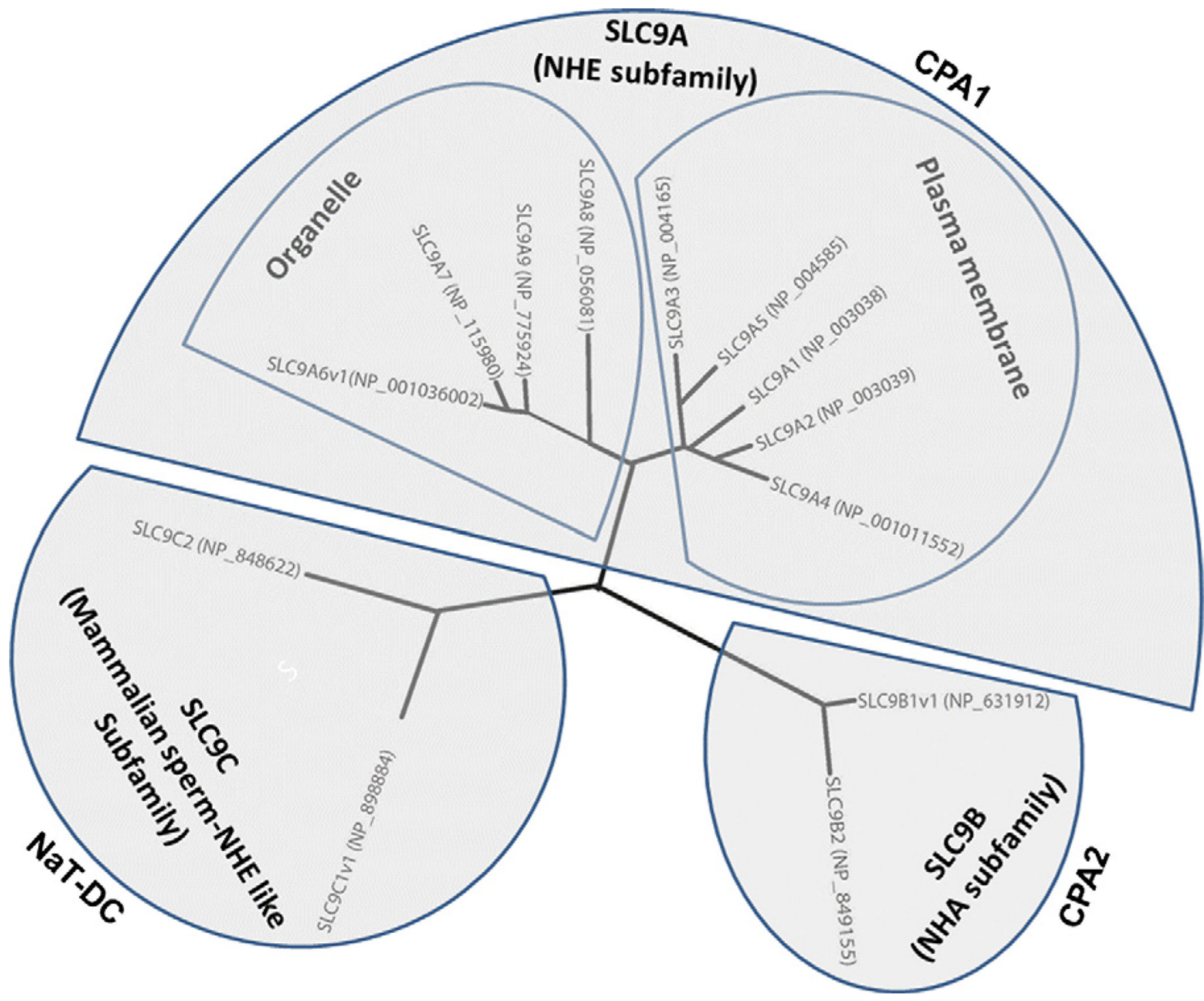

Fig. 1.

Human sequences of SLC9 family were aligned using COBALT (Papadopoulos and Agarwala, 2007), a constraint-based alignment tool for multiple protein sequences. For NHE6, NHA1 and sperm-NHE which have spliced variants, the longest spliced variant (v1) is used for alignment. The radial tree was drawn by Drawtree. 
a

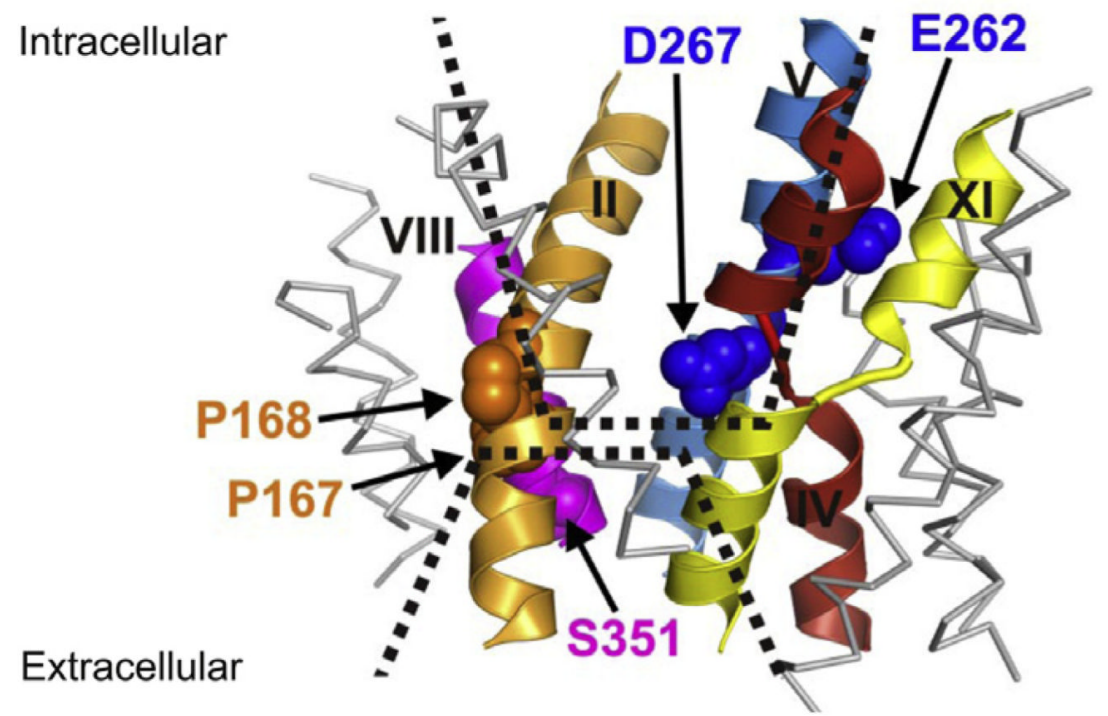

b

EcNhA crystal structure

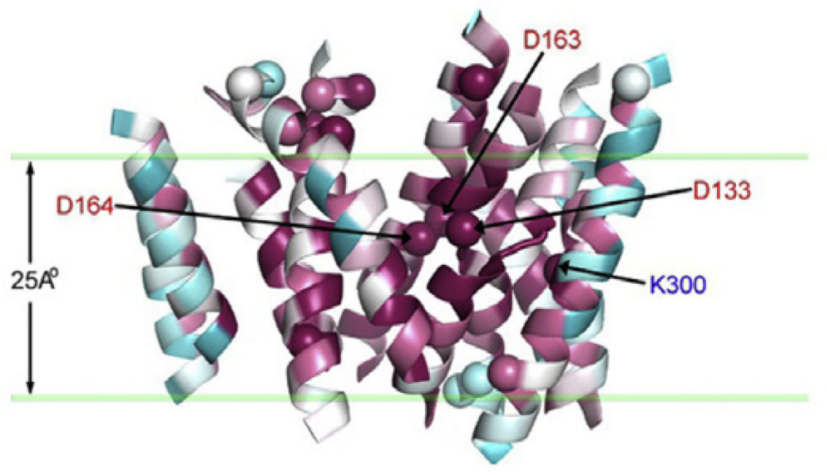

3D-Model of NHE1

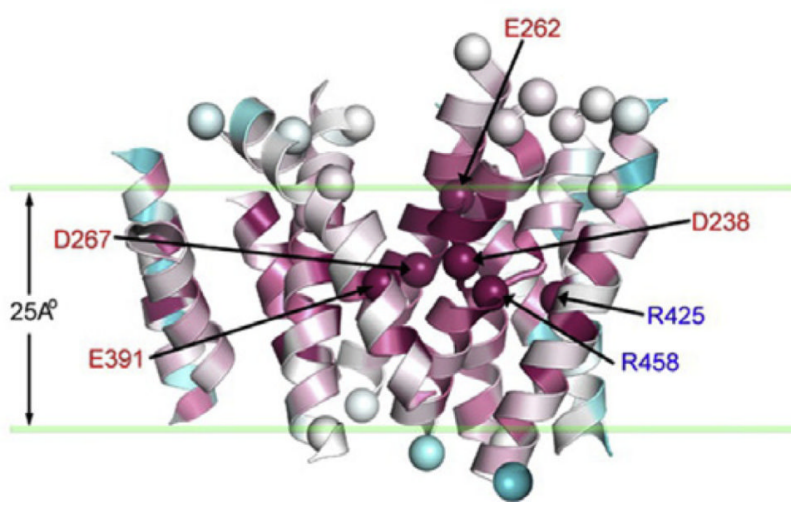

Fig. 2.

(a) Model of the transport domain of NHE1 showing the area of exchange as two opposing funnel structures facing the intracellular and extracellular surfaces with membrane spanning domains indicated by roman numerals with critical amino acids shown. (b) Comparison of NhaA and NHE1 transport domains, modeled from the crystal structure of NhaA. The homologus amino acids crucial to exchange of NhaA and NHE1 are show. (With permission from Donowitz et al., 2009, orginally from Landau et al., 2007) 


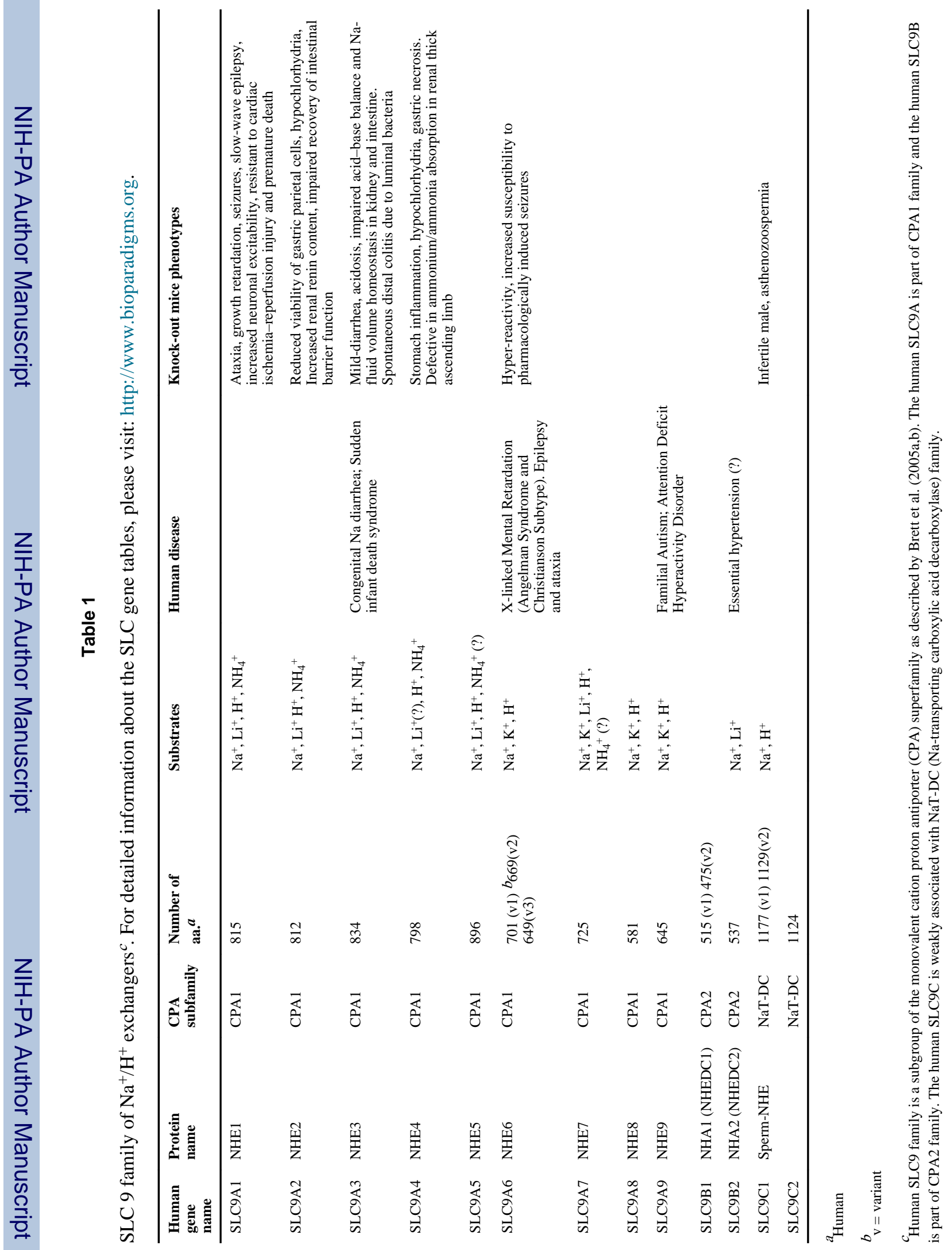

